\title{
Seasonal dependence of the predictable low-level circulation patterns over the tropical Indo-Pacific domain
}

\author{
Tuantuan Zhang $^{1} \cdot$ Bohua Huang $^{2} \cdot$ Song Yang $^{1,3,4} \cdot$ Charoon Laohalertchai $^{5}$
}

Received: 11 April 2017 / Accepted: 19 August 2017 / Published online: 2 September 2017

(c) The Author(s) 2017. This article is an open access publication

\begin{abstract}
The seasonal dependence of the prediction skill of $850-\mathrm{hPa}$ monthly zonal wind over the tropical IndoPacific domain is examined using the ensemble reforecasts for 1983-2010 from the National Centers for Environmental Prediction (NCEP) Climate Forecast System Reanalysis and Reforecast (CFSRR) project. According to a maximum signal-to-noise empirical orthogonal function analysis, the most predictable patterns of atmospheric low-level circulation are associated with the developing and maturing phases of $\mathrm{El}$ Niño-Southern Oscillation (ENSO). The CFSv2 is capable of predicting these ENSO-related patterns up to 9-months in advance for all months, except for May-June when the effect of the spring barrier is strong. The other predictable climate processes associated with the low-level atmospheric circulation are more seasonally dependent. For winter and spring, the second most predictable patterns are associated with the ENSO decaying phase. Within these seasons, the monthly evolution of the predictable patterns is characterized by a southward shift of westerly wind anomalies, generated by
\end{abstract}

Song Yang

yangsong3@mail.sysu.edu.cn

1 School of Atmospheric Sciences, Sun Yat-sen University, 135 West Xingang Road, Guangzhou 510275, Guangdong, China

2 Department of Atmospheric, Oceanic, and Earth Sciences and Center for Ocean-Land-Atmosphere Studies, George Mason University, Fairfax, VA, USA

3 Guangdong Province Key Laboratory for Climate Change and Natural Disaster Studies, Sun Yat-sen University, Guangzhou, Guangdong, China

4 Institute of Earth Climate and Environment System, Sun Yat-sen University, Guangzhou, Guangdong, China

5 Thai Meteorological Department, Bangna, Bangkok, Thailand the interaction between the annual cycle and the ENSO signals (i.e., the combination-mode). In general, the CFSv2 hindcast well predicts these patterns at least 5 months in advance for spring, while shows much lower skills for winter months. In summer, the second predictable patterns are associated with the western North Pacific (WNP) monsoon (i.e., the WNP anticyclone/cyclone) in short leads while associated with ENSO in longer leads (after 4-month lead). The second predictable patterns in fall are mainly associated with tropical Indian Ocean Dipole, which can be predicted 3 months in advance.

Keywords Most predictable patterns $\cdot$ Seasonal dependence $\cdot$ NCEP CFSv2 hindcasts

\section{Introduction}

The tropical Indo-Pacific domain is one of the key regions controlling the global climate variability (Ramage 1968; Neelin et al. 1998; Torrence and Webster 1998; Lau et al. 2000, 2002; Wang et al. 2000; Wang and Zhang 2002; Kosaka and Xie 2013). The large-scale atmospheric circulation over this region plays an important role in not only influencing the variability of the tropical climate systems but also transferring their impacts remotely through teleconnections (Wang and Zhang 2002; Cai et al. 2011; Sun and Zhou 2013). Within the tropical Indo-Pacific domain, the low-level atmospheric circulation plays a major role in facilitating the intensive ocean-atmosphere interactions. For instance, the major equatorial climate variations, such as El Niño-Southern Oscillation (ENSO) and the Indian Ocean dipole (IOD), are usually associated with characteristic zonal wind anomalies in the equatorial region (e.g., Rasmuson and Carpenter 1982; Saji et al. 1999; Huang and Kinter 
2002; Yamagata et al. 2003). Interacting with the equatorial thermocline slope and the sea surface temperature (SST), the equatorial zonal wind near the surface is a critical ingredient in the loop of the Bjerknes feedback (Bjerknes 1969). Off the equator, the development of the anomalous western North Pacific anticyclone (WNP-AC) is another key feature over the tropical Indo-Pacific region, which provides a critical link between the tropical eastern-central Pacific SST anomalies and the East Asian monsoon (Wang et al. 2000; Zhang et al. 2016).

A common characteristic of these tropical wind anomalies is their strong association with the annual cycle. Besides the prominent seasonal phase-locking of both ENSO and IOD, a southward shift of the equatorial westerly surface wind anomalies over the central Pacific also occurs in boreal winter, at the peak phase of major El Niño events, which may account for the rapid termination of these events (e.g., Harrison 1987; Harrison and Vecchi 1999). This meridional shift results from a nonlinear interaction between the low-frequency ENSO signals and the annual cycle of the warm pool, which generates the so-called combination mode (C-mode) at near-annual frequencies (McGregor et al. 2012; Stuecker et al. 2013, 2015). On the other hand, the WNP-AC anomalies have been attributed to the Rossby wave response to anomalous atmospheric heating (e.g., Wang et al. 2000), the Indian Ocean (IO) capacitor effect (e.g., Xie et al. 2009) and a feature of the C-mode (e.g., Stuecker et al. 2015), respectively. Though physically distinctive, these three processes seem not mutually exclusive. Furthermore, they develop at similar seasonal background. Further understanding of the WNP-AC predictability requires an entangling of their individual contributions that make the long persistence of the WNP-AC anomalies from the fall of an ENSO year well into the following spring and summer. Overall, the dependence of the tropical anomalies on the annual cycle prompts us to take into account the seasonal influence in studying the tropical predictability and prediction.

Previous studies have investigated prediction and predictability of the climate variations within the Indo-Pacific region under the seasonal framework (e.g., Wang et al. 2005; Yuan et al. 2011; Jiang et al. 2013a; Zuo et al. 2013; Jia and Lin 2013; Yang and Jiang 2014). For instance, Liang et al. (2009) found that the first and second most predictable patterns of the Asian and Indo-Pacific summer precipitation are characterized by different climate features of the onset and decay years of ENSO, respectively. Several studies have also demonstrated that the wet season rainfall over the Maritime Continent is inherently less predictable than the dry season rainfall, consistent with much lower prediction skill of the Maritime Continent rainfall in the wet season (Haylock and McBride 2001; Hendon 2003; Jiang et al. 2013b; Zhang et al. 2016a, b). Moreover, Zhu et al. (2015a) have investigated the seasonality of the predictable patterns of the tropical Indian Ocean (TIO) SST. They reported that the most predictable pattern is featured by a TIO basin-wide warming in spring and by the IOD mode in the fall. They further noticed that, while the TIO prediction is skillful at least 9-month ahead, the IOD could only be predicted at leads of one or two seasons.

Although the seasonal predictability and prediction of SST and precipitation have been examined quite extensively, few studies have paid attention to the prediction and predictability of the low-level atmospheric circulation patterns over the Indo-Pacific region, especially their seasonality. This is somewhat surprising because low-level wind is a critical component of the tropical dynamic and thermodynamic airsea feedbacks (e.g., Gill 1980; Lindzen and Nigam 1987; Xie and Philander 1994) and thus its predictability deserves a better understanding. Moreover, unlike the parameterized precipitation, wind is a dynamic variable, which is also prognostic and requires observation-based initialization for prediction. As a result, wind prediction skill may be less model-dependent and more reflective of the general quality of our current seasonal forecast systems.

In this study, we investigate the seasonal evolution of the predictable patterns of atmospheric low-level circulation over the tropical Indo-Pacific domain by applying the maximum signal-to-noise (MSN) empirical orthogonal function (EOF) method. We also examine the related global climate variations and to what extent these patterns of different seasons can be predicted by the National Centers for Environmental Prediction (NCEP) Climate Forecast System version 2 (CFSv2). Furthermore, we try to identify the mechanisms that are responsible for the different skills of those predictable patterns and their dependences on the annual cycle.

This paper is organized as follows. The CFSv2 hindcast, the observational data, and the method are described in Sect. 2. Section 3 evaluates the prediction skills of low-level wind in the CFSv2 hindcast for different months. ENSOrelated patterns predictable with multi-seasonal leads are depicted in Sect. 4. The predictable patterns associated with the WNP monsoon and IOD are depicted in Sect. 5. Finally, a summary of the study and further discussions are provided in Sect. 6.

\section{Model, data and methods}

\subsection{Model}

The NCEP CFSv2 is a fully coupled dynamical prediction system that has been providing operational seasonal prediction of the world's climate since March 2011 (Saha et al. 2006, 2014). In CFSv2, the atmospheric component is the NCEP Global Forecast System at T126 resolution, the oceanic component model is the Geophysical Fluid Dynamics 
Laboratory Modular Ocean Model versions 4.0 with a horizontal grid of $0.25^{\circ}-0.5^{\circ}$, and the land component is the four-layer Noah land surface model (Saha et al. 2014). Outputs from the CFSv2 9-month hindcast over a period of 1983-2010 are analyzed in this study. Beginning on 1 January of every year, the 9-month hindcasts have initial conditions at 0000 UTC, 0600 UTC, 1200 UTC, and 1800 UTC on every 5th day, forming a monthly 24 -member ensemble. Details about the 9-month hindcast runs can be seen in Zhang et al. (2016a), and further information about the initial time can be found at http://cfs.ncep.noaa.gov/cfsv2.info/. For convenience, the hindcast ensemble means at 0-month lead, 1-month lead, and so on to a 9-month lead are denoted as LM0, LM1, through LM9, respectively.

\subsection{Data}

The observation-based analyses used in this study include the monthly data of 850-hPa winds and sea level pressure (SLP) from the NCEP Climate Forecast System Reanalysis (Saha et al. 2010), the SST from the National Oceanic and Atmospheric Administration optimally interpolated SST analysis (Reynolds et al. 2007), and the rainfall from the Climate Prediction Center (CPC) Merged Analysis of Rainfall (CMAP) (Xie and Arkin 1997).

\subsection{Methods}

In this study, the empirical orthogonal function (EOF) analysis with maximized signal-to-noise ratio (MSN EOF hereafter) is applied to identify the most predictable patterns of $850-\mathrm{hPa}$ zonal wind. The MSN EOF is a statistical technique specifically designed to extract the common signals from an ensemble of simulations. In general, for an ensemble of simulations under a given forcing, an ensemble mean is supposedly composed of a forced (signal) and a residual random part (internal noise) if the number of the ensemble members is not very large. The MSN EOF minimizes the effects of noise in a moderate ensemble size, and derives patterns that optimize the signal-to-noise ratio from all ensemble members (Allen and Smith 1997; Venzke et al. 1999; Sutton et al. 2000; Chang et al. 2000; Huang 2004). Details of this method were documented in Allen and Smith (1997), Venzke et al. (1999), and Huang (2004).

Applied to an ensemble of hindcasts at a given lead-time, the "forced" signals correspond to the common signals of all hindcast members, i.e., the predictable signals, and the internal noise represents the unpredictable deviations among the ensemble members. Therefore, a larger variance of the MSN EOF mode indicates higher predictability, and the leading MSN EOF modes represent the most predictable patterns. The MSN EOF method has been applied successfully to the ensemble hindcasts to extract their predictable signals for different variables and in different areas (e.g., Hu and Huang 2007; Liang et al. 2009; Zuo et al. 2013; Zhu et al. 2015). Different from most previous MSN EOF applications, which usually target at a particular month or season, our analysis is applied to hindcasts for every calendar month to examine the evolution of the predictable patterns within a full annual cycle. For each calendar month, we also conduct the MSNEOF analysis for every lead month to evaluate the limit of predictability accurately.

Besides, several indices are used in this work. The Niño-3 index, Niño-3.4 index, and Niño-4 index are defined by the SST anomalies averaged over the areas of $5^{\circ} \mathrm{S}-5^{\circ} \mathrm{N}$, $90^{\circ} \mathrm{W}-150^{\circ} \mathrm{W}, 5^{\circ} \mathrm{S}-5^{\circ} \mathrm{N}, 120^{\circ} \mathrm{W}-170^{\circ} \mathrm{W}$, and $5^{\circ} \mathrm{S}-5^{\circ} \mathrm{N}$, $160^{\circ} \mathrm{E}-150^{\circ} \mathrm{W}$, respectively. The WNP-AC index is defined by the SLP averaged over $5^{\circ} \mathrm{N}-20^{\circ} \mathrm{N}, 120^{\circ} \mathrm{E}-160^{\circ} \mathrm{E}$, following $\mathrm{Li}$ et al. (2016). The IOD index is defined as the SST difference between the western equatorial IO $\left(10^{\circ} \mathrm{S}-10^{\circ} \mathrm{N}\right.$, $\left.50^{\circ} \mathrm{E}-70^{\circ} \mathrm{E}\right)$ and the eastern equatorial IO $\left(10^{\circ} \mathrm{S}-0^{\circ}\right.$, $90^{\circ} \mathrm{E}-110^{\circ} \mathrm{E}$ ) (Saji et al. 1999).

\section{Evaluation of prediction skills}

In this section, we evaluate the NCEP CFSv2 predictive skill of 850-hPa zonal wind over the tropical Indo-Pacific domain as a function of lead time and target month. Figure 1 shows the correlation skill of 3-month lead prediction for $850-\mathrm{hPa}$ zonal wind from the CFSv2 hindcast for selected calendar months to represent the annual cycle. In general, skillful regions are concentrated in the equatorial ocean throughout the basin, as well as in the northern tropics of the western Pacific and the IO. It is also interesting to see that the areas of high correlation coefficients migrate seasonally. Indeed, the regions of significant skill are centered over the centralto-eastern equatorial Pacific from boreal winter to spring (Fig. 1a, b, f) but shift to the western Pacific and the IO during summer and fall (Fig. 1d, e), with late spring as a transition period of time (Fig. 1c).

This distinctive seasonality can be more clearly seen from the prediction of several area-averaged indices over different areas of relatively high skills, including the Niño-3.4, Niño-4, warm pool (WP), and eastern IO (EIO) regions, as outlined in Fig. 1 (see the corresponding boxes). Figure 2 shows the prediction skills of $850-\mathrm{hPa}$ zonal wind over those high correlation areas as a function of lead-time and target month. Consistently, the predictive skill of the Niño-3.4 index is high from October to May, even at long leads. However, a quick drop occurs from May to June, leading to quite limited skill during boreal summer and early fall (Fig. 2a), possibly a reflection of the spring predictability barrier (e.g., Webster and Yang 1992). Further to the west, however, the skill for Niño-4 is less seasonally dependent with higher skill during boreal 
(a) Jan

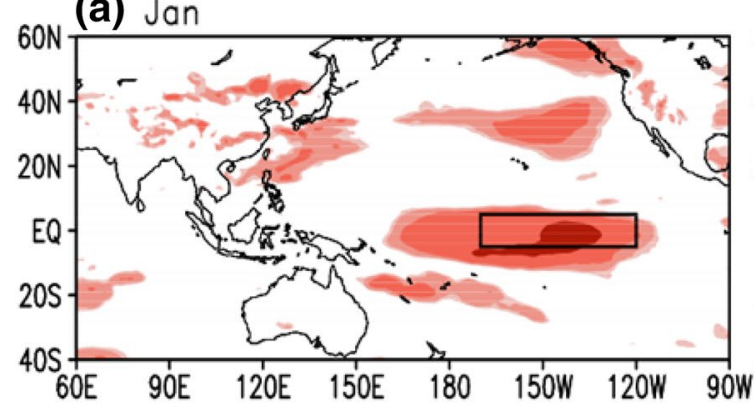

(c) May

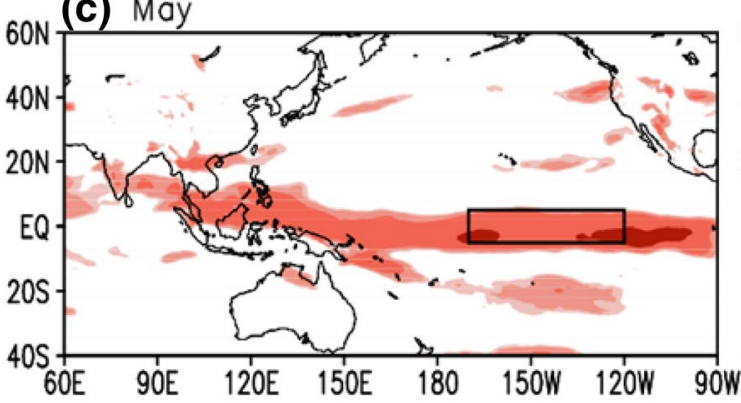

(e) Oct

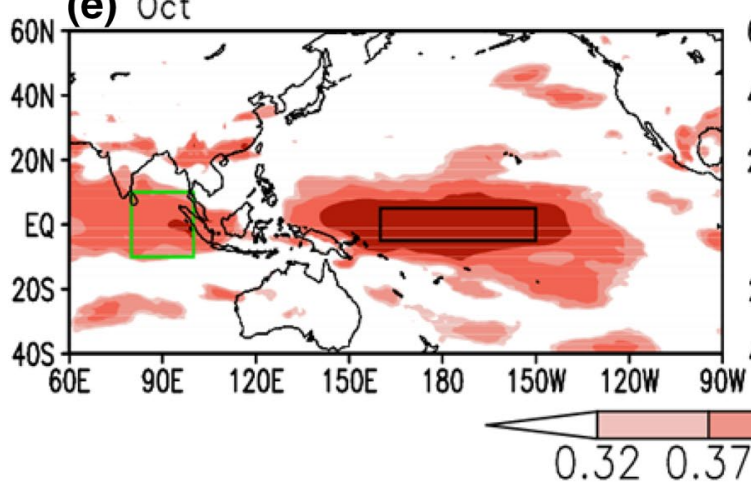

Corr between U850 of CFSR and CFSv2 LM3

(b) Mar

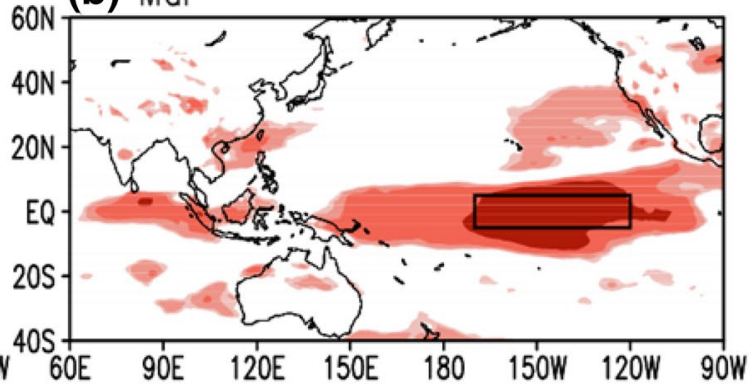

(d) Jul

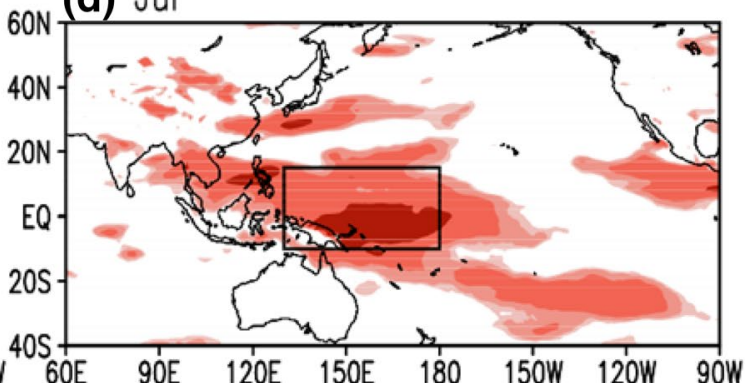

(f) $\mathrm{Dec}$

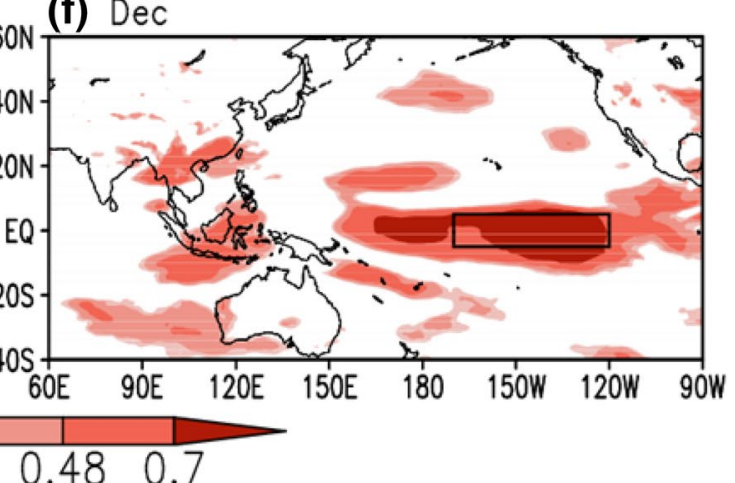

Fig. 1 Correlations between observed $850-\mathrm{hPa}$ zonal wind $(\mathrm{m} / \mathrm{s})$ and predicted $850-\mathrm{hPa}$ zonal wind $(\mathrm{m} / \mathrm{s})$ in CFSv2 hindcast ensemble mean of 3-months lead for a January, b March, c May, d July, e October, and f December. Values exceeding the 90, 95, and 99\% con-

summer (Fig. 2b), which is likely benefited from a general enhancement of the predictive skill in WP during boreal summer (Fig. 2c) when the WNP monsoon prevails (Murakami and Matsumoto 1994). Another enhancement of the WP skill occurs in February-March when the thermal contrast between oceans and land is generally weak during the seasonal transition (LinHo et al. 2008) and the C-mode also becomes active during strong El Niño events. On the other hand, the highest EIO prediction skill appears in October and November, with a secondary enhancement during February-March (Fig. 2d). The above analysis suggests a strong seasonality of the predictable low-level atmospheric circulation patterns as well as their prediction skills over the tropical Indo-Pacific region. fidence levels are shaded. Black boxes in (a), (b), (c), and (f) denote the area for Niño-3.4.and in (e) for Niño-4. The black box in (d) and the green box in (e) denote high correlation areas for the warm pool (WP), and eastern Indian Ocean (EIO) regions

To identify the spatial structure of these predictable signals and their seasonal dependence, the method of MSN EOF is applied to the ensemble hindcasts to extract the predictable signals of $850-\mathrm{hPa}$ zonal wind over the tropical Indo-Pacific domain $\left(30^{\circ} \mathrm{S}-30^{\circ} \mathrm{N}, 80^{\circ} \mathrm{E}-140^{\circ} \mathrm{W}\right)$ for every calendar month and lead time. We concentrate on the first two MSN EOF modes because they are statistically significant at the 95\% level using the F-test (Huang 2004). One should also note that these most predictable patterns are identified from the ensemble hindcasts alone. Their prediction skill, i.e., correlation with observations, needs to be verified. To evaluate how realistically the predictable patterns identified by the MSN EOF, we conduct the following verification: the observed $850-\mathrm{hPa}$ zonal wind anomalies are 


\section{Corr between Obs and CFSv2}

(a) Nino3.4_u850
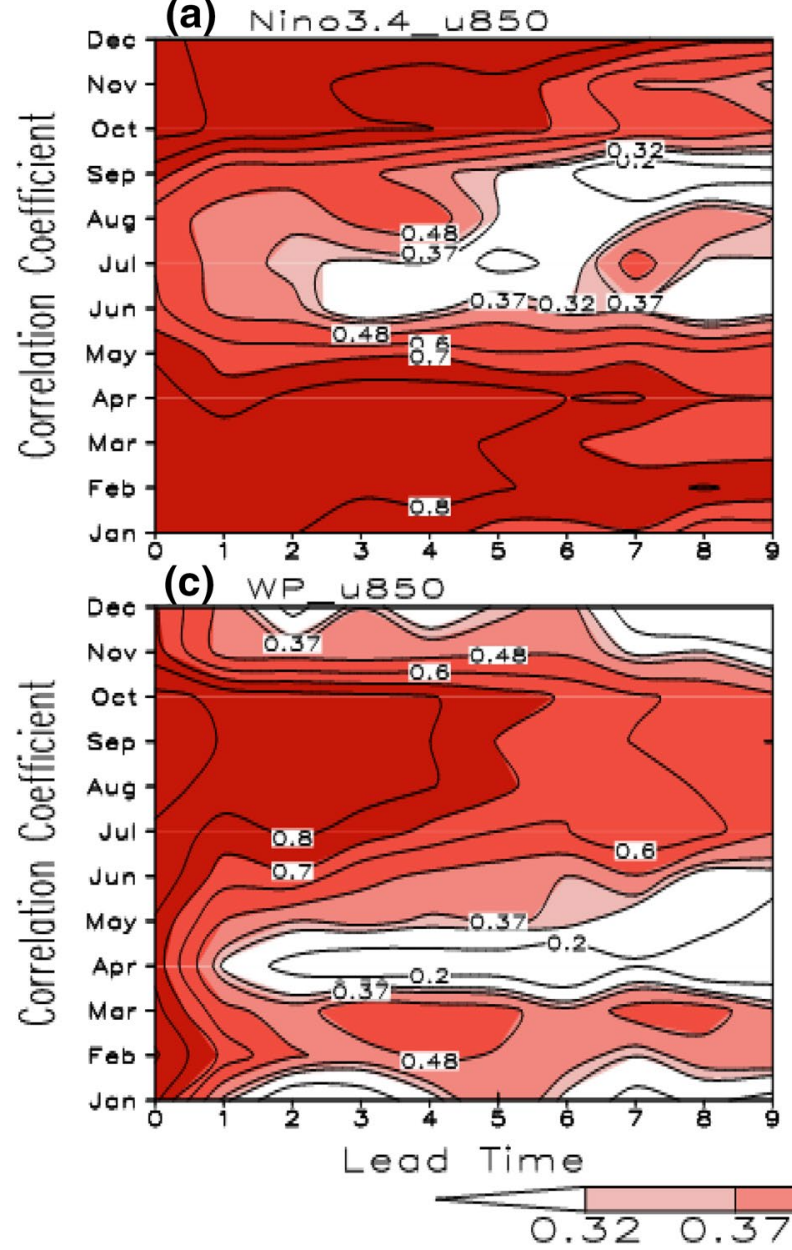

(b) Nino4_u850

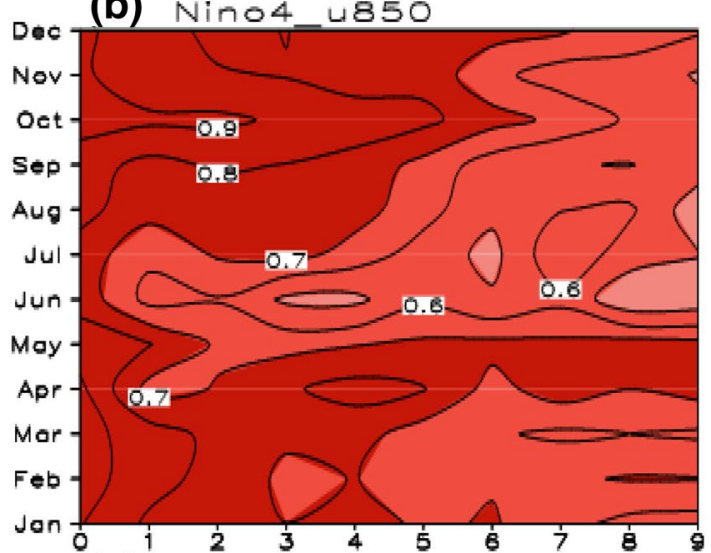

(d) EIO 4850

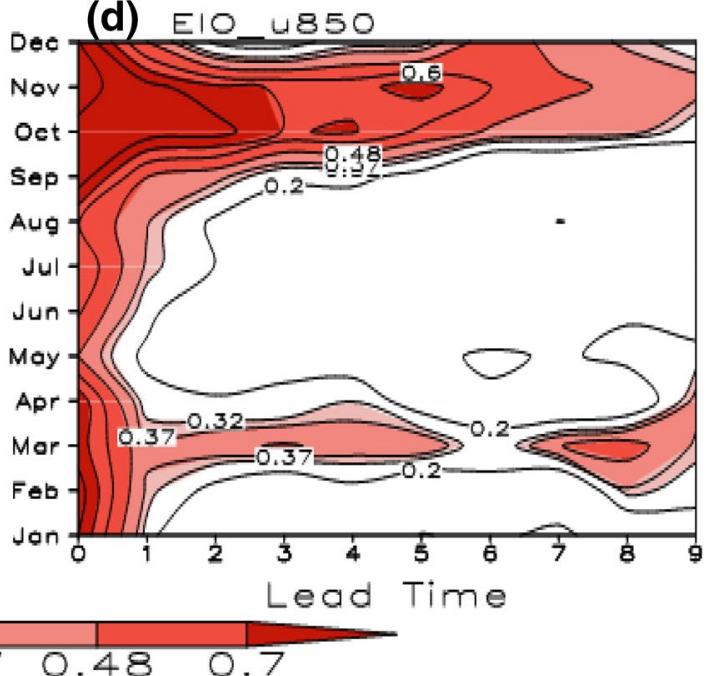

Fig. 2 Coefficients of correlation between observation and ensemble mean hindcast in different lead months and calendar months for area averaged $850-\mathrm{hPa}$ zonal wind $(\mathrm{m} / \mathrm{s})$ of Niño-3.4, Niño-4, warm pool (WP), and eastern Indian Ocean (EIO) regions. Values exceeding the

first projected onto each of the MSN EOF1 and the MSN EOF2 at different target months and lead months, respectively. These projected time series are referred to as the corresponding $\mathrm{PC} 1$ and $\mathrm{PC} 2$ in observations. One measure to the skill of the MSN EOF modes is the coefficient of correlation between the ensemble means projected onto the MSN EOFs (MSN PCs or ensemble mean PCs hereafter) and their corresponding PCs in observations, which is shown in Fig. 3 as a function of both lead month and target month.

As shown in Fig. 3a, the first mode (the most predictable pattern) of the $850-\mathrm{hPa}$ zonal wind over the IndoPacific region is well predicted up to LM9 for all calendar months, except for May-June when the skillful predictions are limited to LM4. In comparison to MSN EOF1, the predictability of MSN EOF2 (Fig. 3b) is more seasonally dependable beyond LM2. For instance, the CFSv2
90, 95, and 99\% confidence levels are shaded. The $x$-coordinate indicates the corresponding lead months and $y$-coordinate indicates the corresponding months

hindcast well predicts the second most predictable modes for target months in spring at the leads of multiple seasons, but shows much lower prediction skills for winter and fall months such as January and September (Fig. 3b). It is also interesting to see that a clear rebound of skill for target months June-July after LM4. More extended limits of skilled predictions also occur in October-November.

The above analysis indicates that the MSN EOF is an effective technique to isolate the signals (predictable patterns) from the CSFv2 hindcasts. The two leading MSN EOF modes provide skill predictions of the observational features and are complementary to each other with respect to seasonal dependence. Besides, those features depicted above raise a question: what mechanisms should be responsible for the different prediction skills of those predictable patterns? 


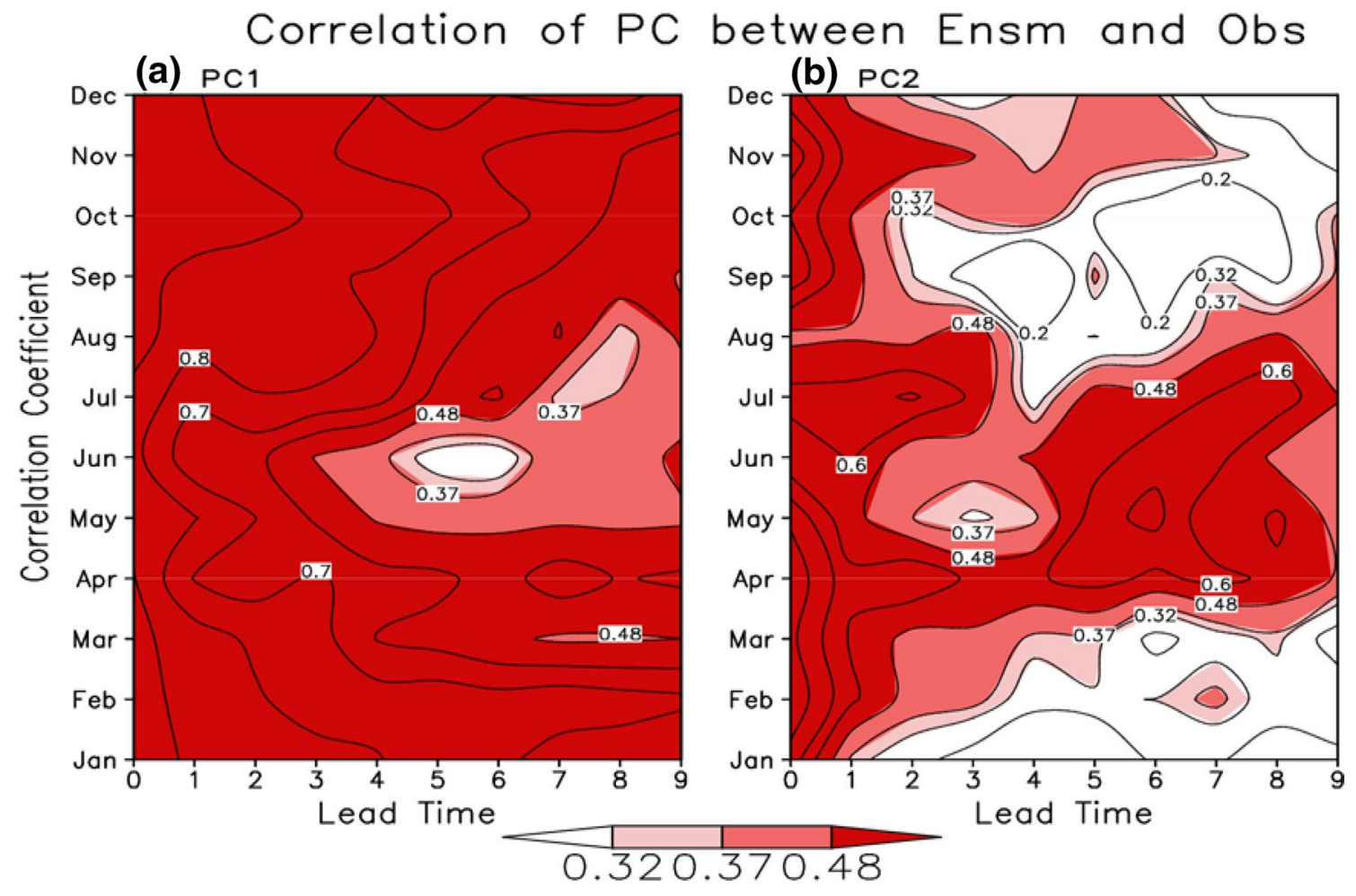

Fig. 3 Coefficients of correlation between ensemble mean PCs and projected observational PCs for MSN PC1 (left panel) and MSN PC2 (right panel). Values exceeding the 90, 95, and 99\% confidence lev-

\section{ENSO-related patterns predictable with multi-seasonal leads}

Previous studies have demonstrated that the CFSv2 is capable of simulating and predicting the major climatological features over the Indo-Pacific region (Yuan et al. 2011; Wang et al. 2011; Weaver et al. 2011). In this section, we depict the predictable patterns in the CFSv2 with multiseason leads. The first mode of MSN EOF is largely related to ENSO during the year, demonstrated by the significant correlations between the MSN PC1s and the Niño-3.4 SST indices (as well as the Niño-3 SST indices and Niño-4 SST indices; figures not shown) for all months and lead times except for the longer lead months in June-July (Fig. 4a). It is also interesting to note the similarity between Figs. 3a and 4a. The seasonal decline of prediction skill in late spring and early summer shown in Figs. 3a and 4a is likely associated with the spring barrier in ENSO prediction (e.g., Lau and Yang 1996; Yu and Kao 2007). Therefore, the patterns of MSN EOF1 mainly reflect the predictable EOF signals that are predictable with the lead of multiple seasons, except in early boreal summer.

On the other hand, the correlations between the MSN PC2s and the Niño-4 SST indices exceed the 95\% confidence level of the Student's $t$ test (0.37) in all leads of spring els are shaded. The $x$-coordinate indicates the corresponding lead months and $y$-coordinate indicates the corresponding months

months, short leads of winter months except for December, and long leads (LM5-LM9) of summer months (Fig. 4b). Correlations between the MSN PC2s and the central Pacific ENSO indices as defined by Kao and Yu (2009) show similar features (figure not shown). However, there are insignificantly correlations between the MSN PC2s and the Niño3.4 (or Niño-3) SST indices in those months (figures not shown). These features imply that the second most predictable patterns in spring, winter, and longer leads of summer months are closely linked to SST anomalies over the equatorial central Pacific rather than those over the equatorial eastern Pacific.

\subsection{The most predictable ENSO pattern}

As an example of the predictable signals at multi-season leads, the most predictable patterns of $850-\mathrm{hPa}$ zonal wind for different lead months in January are shown in Fig. 5. The percentages of variance of the ensemble mean $850-\mathrm{hPa}$ zonal wind anomalies explained by these MSN EOF1s are 51.2, 60.3, 62.8, and 59.6 for LM0, LM3, LM6, and LM9, respectively. The spatial pattern of MSN EOF1 in LM0 is characterized by opposite variations of the anomalous zonal wind over the equatorial Pacific extending eastward from $150^{\circ} \mathrm{E}$ and that over the regions to its west, north, and south 


\section{Corr between ENSO indices\&IOD\&WNPAC and PC}

(a) Nino3.4_PC1

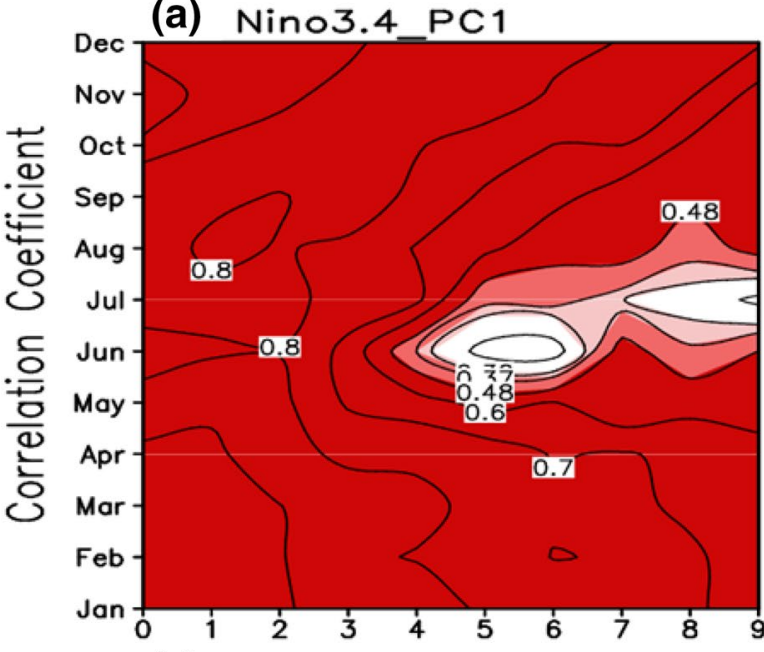

(c) WNPAC_PC2

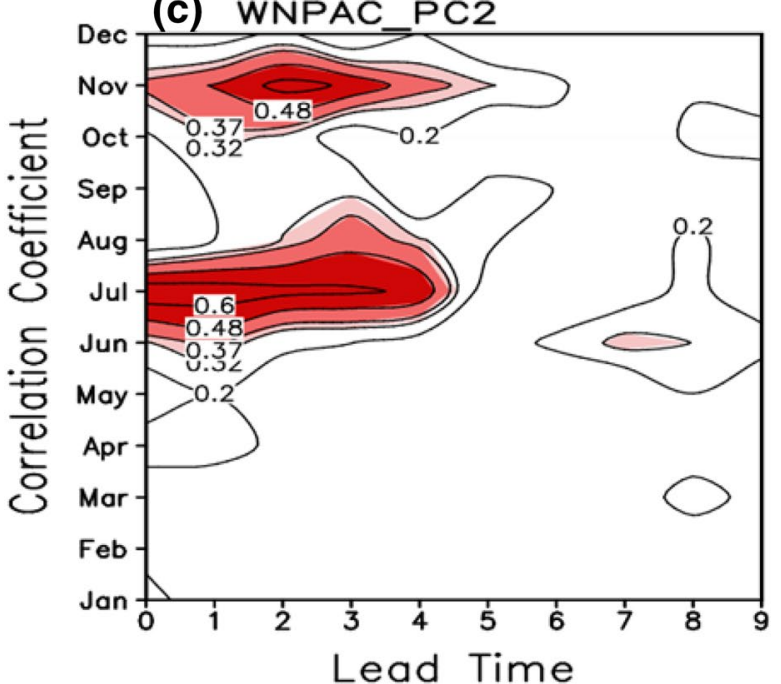

(b) Nino4_PC2

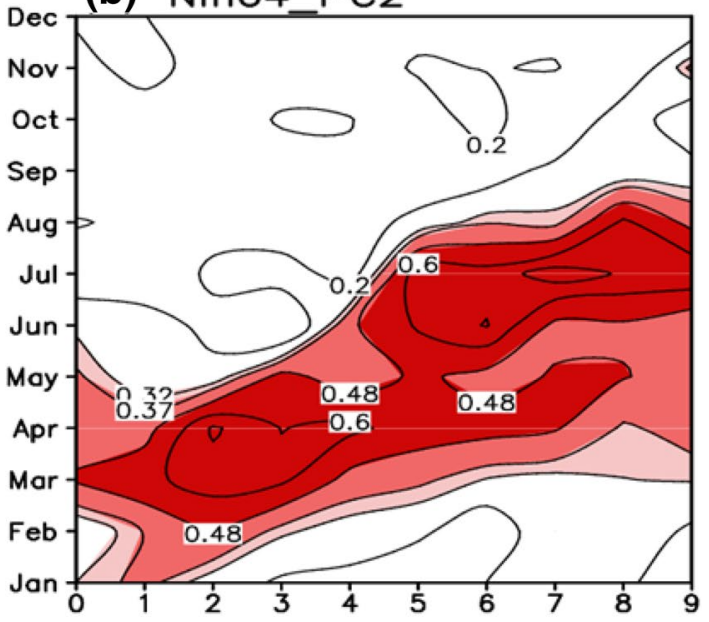

(d) $10 \mathrm{D} \_\mathrm{PC} 2$

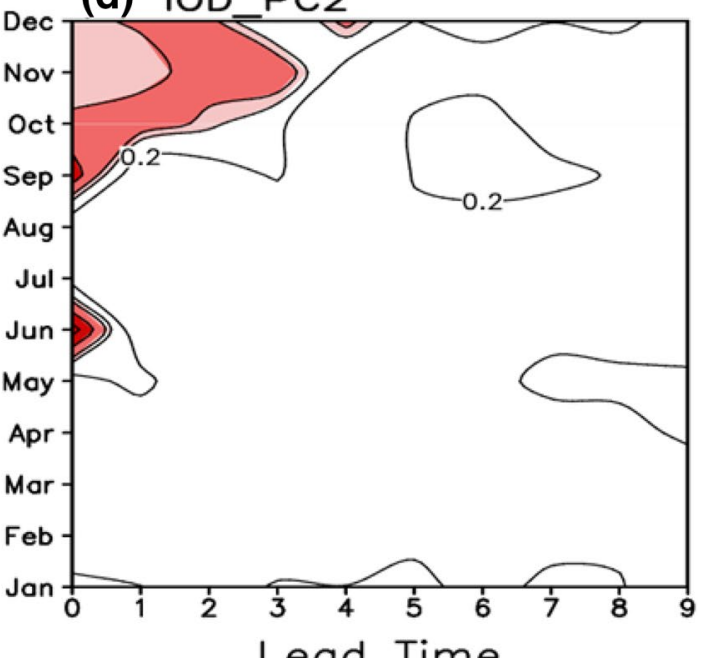

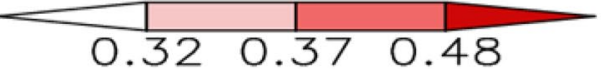

Fig. 4 Coefficients of correlation between a Niño-3.4 index and ensemble mean PC1; b Niño-4 index and ensemble mean PC2; c WNP-AC index and ensemble mean PC2; and d IOD index and

(Fig. 5a). The peaks of MSN PC1 (measured by the thick black curve) appear in January of 1983, 1987, 1992, 1995, 1998, 2003, and 2010 and valleys in 1984, 1989, 1996, 1999-2001, 2006, and 2008 (Fig. 5b). According to the criterion of the National Oceanic and Atmospheric Administration (NOAA) Climate Prediction Center (http://www.cpc. ncep.noaa.gov/products/analysis_monitoring/ensostuff/ensoyears.shtml), most of these peaks and valleys correspond to the El Niño and La Niña years, respectively. There exist obvious similarities among the leading modes of MSN EOF in different leads, for both spatial patterns and time series (Fig. 5). Spatially, however, the loadings over the Maritime ensemble mean PC2. Values exceeding the 90, 95, and 99\% confidence levels are shaded. The $x$-coordinate indicates the corresponding lead months and $y$-coordinate indicates the corresponding months

Continent strengthen with increasing lead while those over the equatorial IO weaken quickly after LM0, suggesting that the IO branch is much less predictable than the other features in this pattern.

To determine whether the highly predictable pattern in January is robust and how skillfully it forecasts the observed features, we project each of the individual ensemble members and observations onto the MSN EOF1 patterns. The coefficients of these projections are counterparts to the MSN $\mathrm{PC} 1 \mathrm{~s}$ and are referred to as the projected PC1s for either of the ensemble members (dashed black curves) or observations (solid red lines; right panels in Fig. 5) for convenience. 


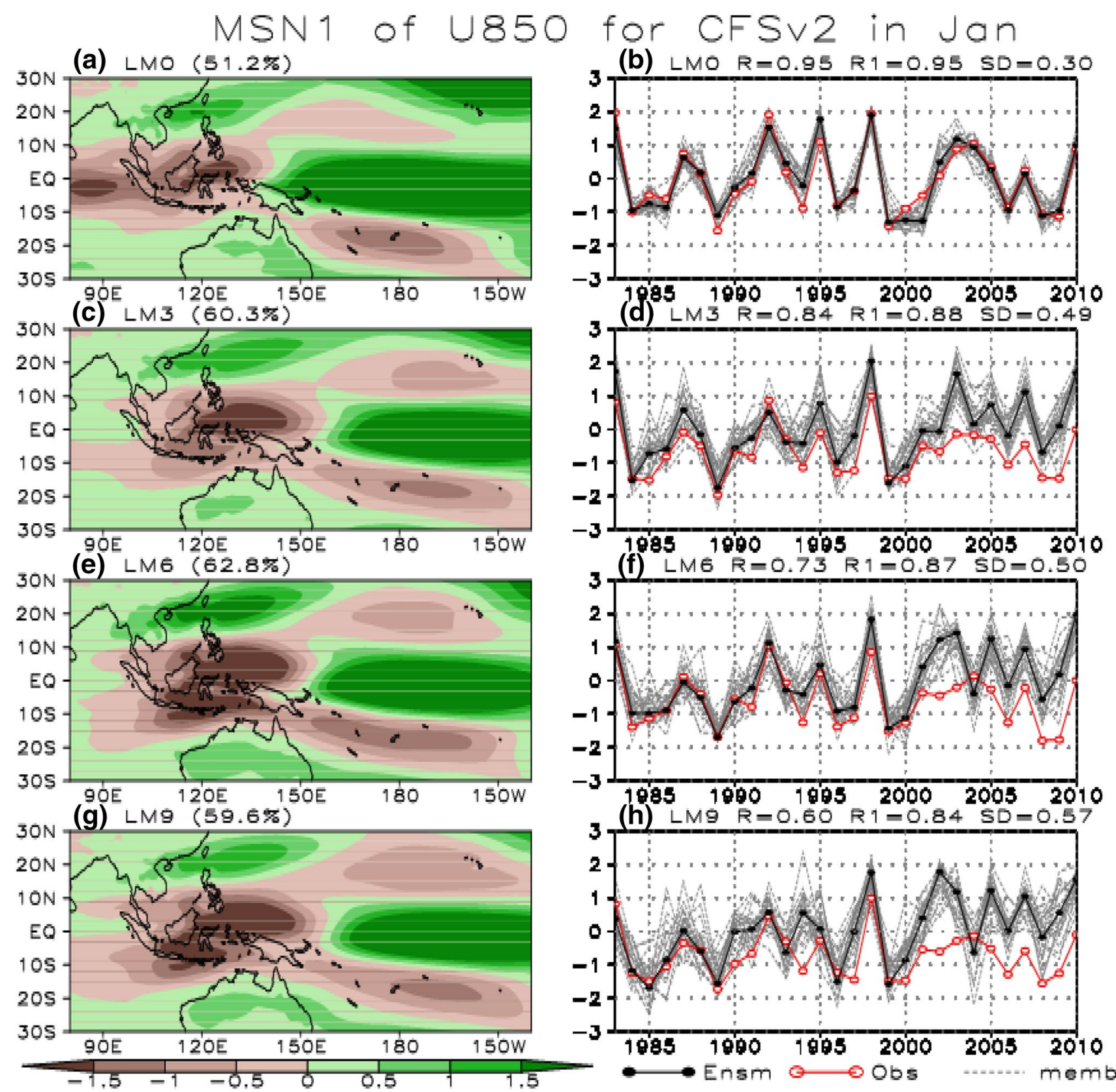

Fig. 5 First MSN EOF modes of the CFSv2 reforecast $850-\mathrm{hPa}$ zonal wind $(\mathrm{m} / \mathrm{s})$ for lead months of $0,3,6$, and 9 in January. In the right panels, the solid black lines are the PCs of ensemble means. The solid red lines and dashed black lines represent the PCs that are computed by projecting the $850-\mathrm{hPa}$ zonal wind in observation and ensemble members upon the MSN EOF1. R represents the coefficient

of correlation between ensemble mean PC and projected observational PC; R1 represents averaged coefficient of correlation between ensemble mean PC and projected PCs for individual members; SD represents averaged standard deviations of the projected PCs from the ensemble members

The spreads of the projected PC1s among ensemble members are generally small in all leads, in spite of an increase with lead month $(\mathrm{SD}=0.30,0.49,0.50$, and 0.57 for $\mathrm{LM} 0$, LM3, LM6, and LM9, respectively). Consistently, the averages of correlations between the MSN PC1s and the projected PC1s for ensemble members $(\mathrm{R} 1=0.95,0.88,0.87$, and 0.84 for LM0, LM3, LM6, and LM9, respectively),

though all statistically significant, decrease slightly with increasing lead time. Such reduction is due to the growth of initial errors in a nonlinear system but the growth rate is low, implying high predictability of the depicted pattern. Moreover, the coefficients of correlation between the MSN PC1s and their corresponding projected observational PC1s are $0.95,0.84,0.73$, and 0.60 for LM0, LM3, LM6, and 
LM9, respectively (also see Fig. 3). These correlation coefficients exceed the $99 \%$ confidence level of the $t$ test $(0.48)$, indicating that the interannual variation of $850-\mathrm{hPa}$ zonal wind associated with this most predictable pattern in the CFSv2 hindcast is highly coherent with that in observations. Visually, however, there is a skill difference before and after 2000, especially with the longer lead months (Fig. 5f, h), which is consistent with Barnston et al.'s (2012) finding that the prediction skill of ENSO has declined in the 2000s.

The relationship between the most predictable pattern of 850-hPa zonal wind and other ocean-atmosphere anomalies further demonstrates its ENSO characteristics. Figure 6 shows the correlations of observed (Fig. 6a, b) and predicted (Fig. 6c-j) SLP/rainfall with the ensemble mean PC1s, and regressions of observed (Fig. 6a, b) and predicted (Fig. 6c-j) 850-hPa winds/SST against the ensemble mean PC1s, for different lead months in January. The positive values of the PC1s are clearly linked to the negative phase of the Southern Oscillation, with the negative SLP anomalies over the eastern Pacific and positive SLP anomalies from the IO to the western Pacific, corresponding to anomalous westerlies (easterlies) over the equatorial Pacific (IO). Furthermore, warm SST anomalies prevail in the equatorial central-eastern Pacific and IO, with cold SST anomalies extending from the western equatorial Pacific toward the northeast (southeast) in the Northern (Southern) Hemisphere. In general, there is an increase in rainfall over the warm SST anomalies, especially the equatorial central-eastern Pacific, and a decrease in rainfall over the rest of the Indo-Pacific region (Fig. 6a, b). These characteristics are typical at the peak of El Niño (La Niña) events, suggesting that ENSO dominates the most predictable pattern of 850-hPa zonal wind over the Indo-Pacific region in January.

For this mode, predictable signals do not significantly decrease with the increase in lead months and they are well predicted in the CFSv2 hindcast even up to LM9 (Figs. 5, 6), which demonstrates the high predictability of this ENSOrelated pattern. In general, these observational features are well simulated by the model hindcasts, but some flaws are also found (Fig. 6b-j). For instance, the model easterly wind anomalies are generally weaker than the observed and more confined to the eastern equatorial IO even though the warming in the IO is more apparent and expands into the northwestern tropical Pacific. The model anomalous WNP-AC is also stronger and shifted eastward. Some of these features, such as the SST difference in the IO, may partly originate from the regressions onto a single member (the observation) and an ensemble mean, i.e., the difference between the detectable and consistent signals (Venzke et al. 1999). On the other hand, these observation-model discrepancies may also reflect the effects of the model systematic bias.

The first MSN EOF mode in January is representative of the most predictable patterns of $850-\mathrm{hPa}$ zonal wind over the tropical Indo-Pacific region in the months of the developing and maturing phases of ENSO. Their relationships with other ocean-atmosphere anomalies are generally well predicted in the model, except some overestimations which may be attributed to the overestimated impact of ENSO (figures not shown; Liang et al. 2009; Zhang et al. 2016a). The high prediction skills of these modes as well as their related features come from the high skill of ENSO predicted by the CFSv2, consistent with previous studies (Xue et al. 2013; Zhang et al. 2016a, b).

\subsection{Predictable ENSO-decaying patterns}

Compared to the MSN EOF1s (the most predictable patterns), which persistently depict the dominant ENSO signals throughout most of the year, the MSN EOF2s (the second predictable patterns of low-level atmospheric circulation) depict different climate signals for different seasons. Some of these seasonal features are predictable with multi-season leads. For instance, the second most predictable patterns show high predictive skill of Niño-4 SST indices in target months of March and April from LM0 to LM9 (Fig. 3b), which are generally characterized by features associated with the decaying phase of ENSO.

The second MSN EOF modes of 850-hPa zonal wind in March are shown in Fig. 7 to demonstrate this feature. The percentages of variance of the ensemble mean explained by these MSN EOF2s are 15.6, 19.8, 16.4, and 18.1 for LM0, LM3, LM6, and LM9, respectively. The most striking features of Fig. 7 are the anomalous easterly zonal winds from the east of the Philippines to the dateline, which are surrounded by anomalous westerly zonal winds. The spatial patterns are similar in different lead months (left panels in Fig. 7). For the time series, the large positive (such as 1984, 1998, and 2008) and negative (1990, 1997, and 2002) values of the MSN PC2 in LM0 generally correspond to the decaying years of El Niño and La Niña events, respectively. Both the spreads among individual members and the discrepancy between observation and CFSv2 ensemble mean are small in $\mathrm{LM} 0(\mathrm{R} 1=0.87, \mathrm{SD}=0.51$, and $\mathrm{R}=0.83)$, but become larger with longer leads (right panels in Fig. 7). The interannual variation of $850-\mathrm{hPa}$ zonal wind associated with this predictable pattern in March is well predicted by the CFSv2 model 5 months in advance (Fig. $3 \mathrm{~b}$ and right panels of Fig. 7).

Figure 8 shows correlation maps for SLP and rainfall, and regression maps for $850-\mathrm{hPa}$ winds/SST, for the ensemble mean PC2s of different lead months in March. The positive values of the PC2 are mainly related to positive SLP anomalies over the central and western tropical Pacific and negative SLP anomalies over the eastern IO, which extend northeastward along the coast of the Asian Continent into the North Pacific. The SLP pattern is associated with surface 
(a) SLP\&UV850 LMO OBS 4

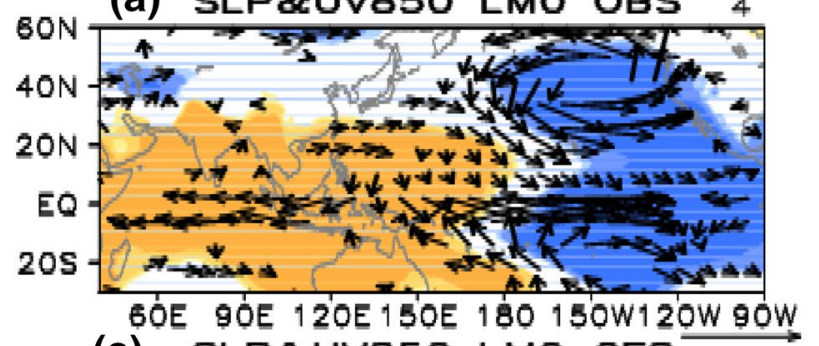

(c) SLP\&UV850 LMO CFS 4

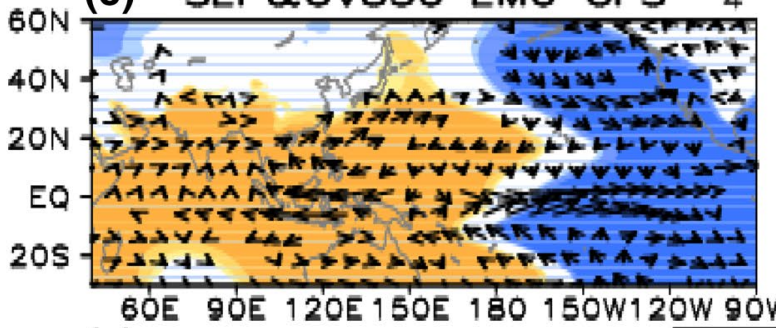

(e) SLP

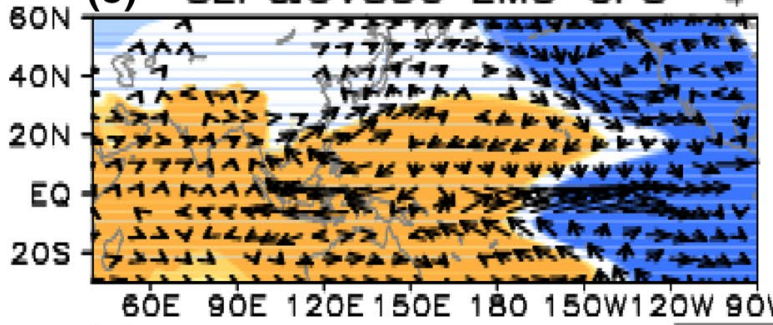

(g) SLP\&UV850 LM6 CFS 4

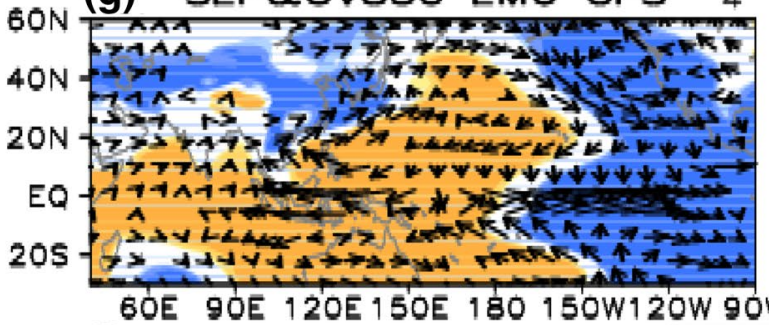

GOE 9OE $120 \mathrm{O} 150 \mathrm{E} 180150 \mathrm{~W} 120 \mathrm{~W} 90 \mathrm{~W}$

(i) SLP\&UV850 LM9 CFS 4

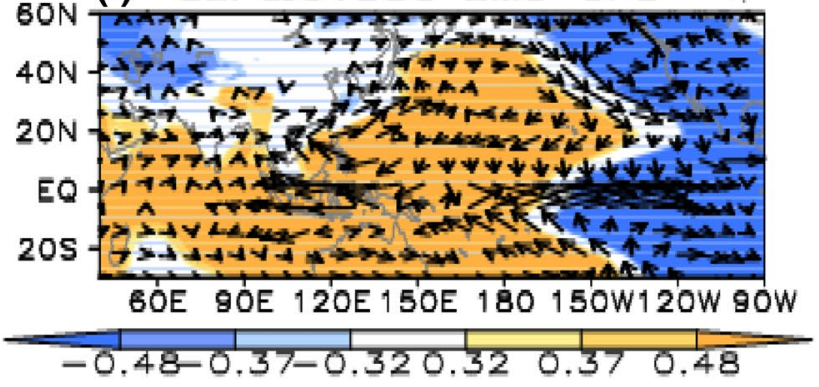

Fig. 6 Correlations of observed (a, b) and predicted (c-j) SLP/rainfall with ensemble mean PC1s and regressions of observed $(\mathbf{a}, \mathbf{b})$ and predicted $(\mathbf{c}-\mathbf{j}) \quad 850-\mathrm{hPa}$ winds/SST against ensemble mean $\mathrm{PC} 1 \mathrm{~s}$ in different lead months for January. Left panels show patterns for SLP

cooling in the equatorial central-eastern Pacific and warming in the tropical eastern South Pacific (Fig. 8a, b). A decrease in rainfall occurs over the equatorial central-eastern Pacific and an increase in rainfall occurs over the tropical eastern (b) SST\&Precip LMO OBS

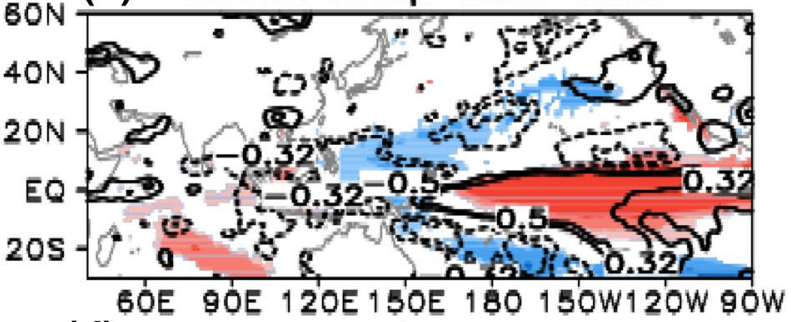

(d)
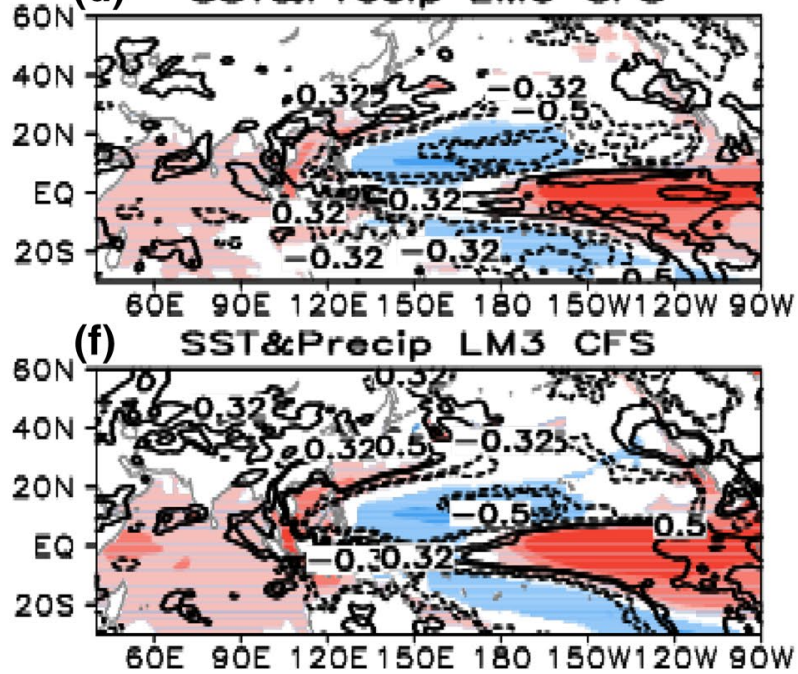

(h) SST\&Precip LMG CFS
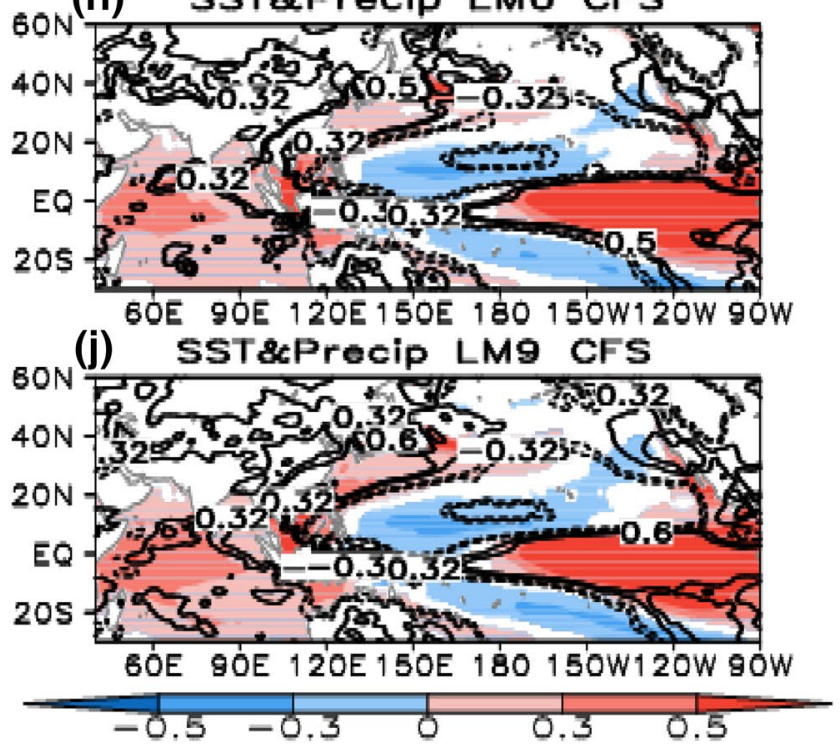

(shading) and 850-hPa winds (vectors) and right panels show patterns for SST (shading) and rainfall (contours). Values exceeding the $90 \%$ confidence level are shown

South Pacific and around the Maritime Continent (Fig. 8b). The equatorial zonal pressure gradients apparently drive the anomalous westerly winds over the equatorial IO and tropical eastern South Pacific, as well as the anomalous easterly 


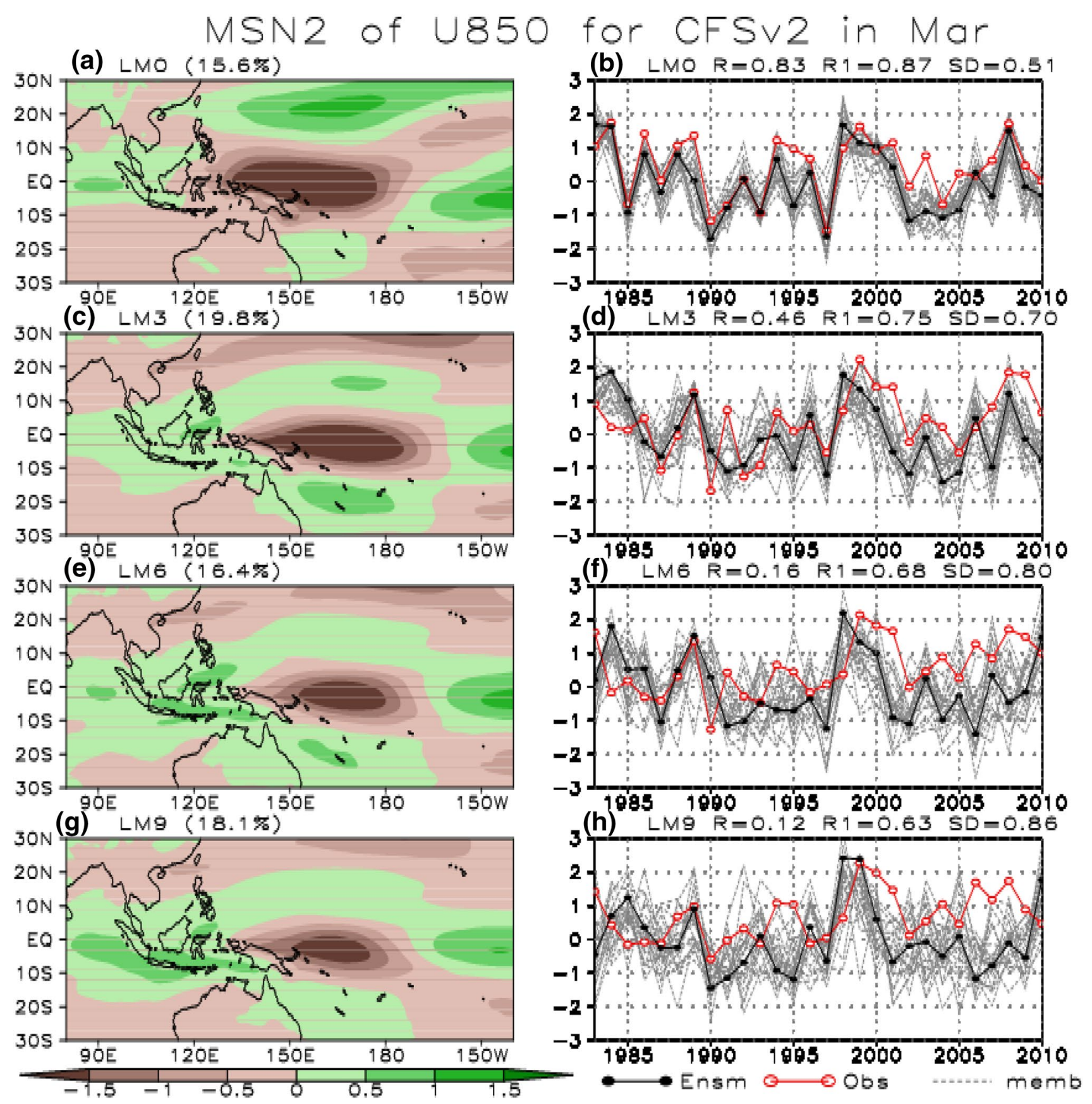

Fig. 7 Same as Fig. 5, but for the second MSN EOF modes in March

winds over the equatorial western Pacific. Together with the westerly winds further north, an anomalous anticyclonic circulation is formed over the North Pacific (Fig. 8a). These features are similar to those related to the ENSO decaying years. The CFSv2 hindcasts predict the cold SST anomalies in the central equatorial Pacific reasonably well up to LM9 (Fig. 8d, f, h, j), which lead to positive SLP anomalies in the region and easterly wind anomalies to its west at LM3 (Fig. 8e) and LM6 (Fig. 8g). The negative SLP anomalies, however, are not well predicted by the model even in LM0 (Fig. 8c, e, g, i). Furthermore, the model hindcasts persistently predict positive SLP and anticyclonic anomalies in the central North Pacific, a feature that does not materialize in observations. These systematic biases occur quickly in the CFSv2 hindcast (i.e., LM0), and the feature has also been seen from Fig. 6. It is puzzling that the signals are particularly weak in LM0 (Fig. 8c) and the predictions at longer leads (e.g., Fig. 8e, g) seem to show better results. Similar 
(a) SLP\&UV850 LMO OBS 4

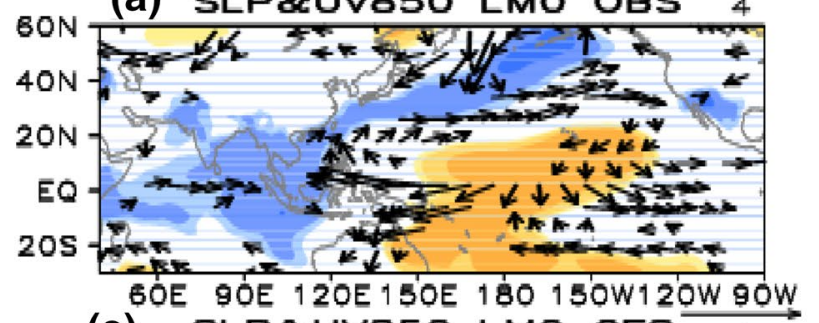

(c)

BOE 9OE $120 \mathrm{O} 150 \mathrm{E} 180150 \mathrm{~W} 120 \mathrm{~W} 90 \mathrm{~W}$
SLP\&UV85O LMO CFS

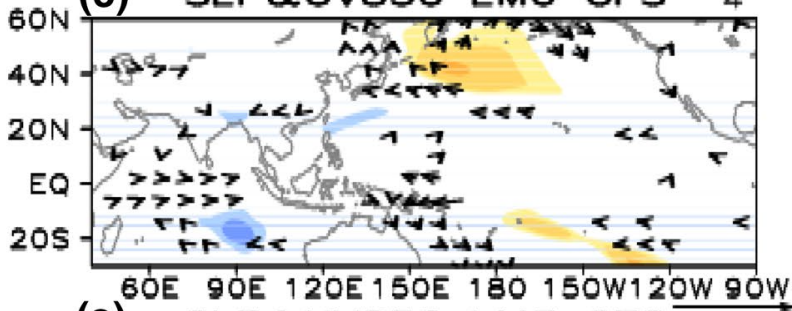

(e) SLP\&UV850 LM3 CFS

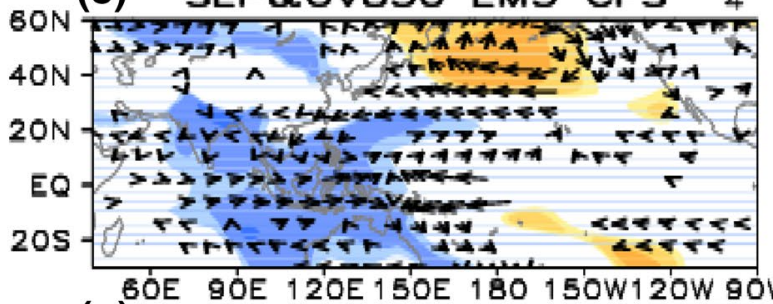

(g) SLP I

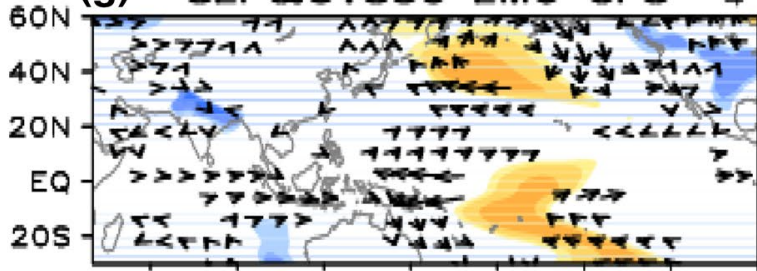

(i) BÓE gOE 12OE 15OE 180150 120W $10 \mathrm{~W}$

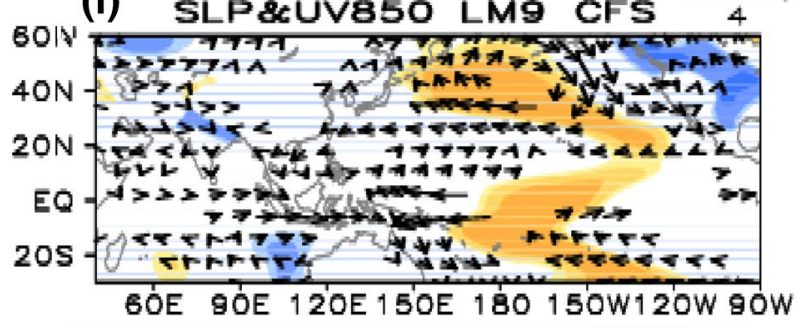

$\begin{array}{lllll}0.48-0.37-0.320 .32 & 0.37 & 0.48\end{array}$ (b) SST\&Procip LMO OBS

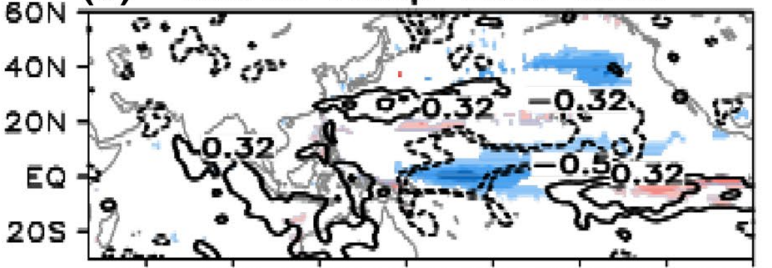

GOE SOE $120 \mathrm{O} 150 \mathrm{E} 180150 \mathrm{~W} 120 \mathrm{~W} 90 \mathrm{~W}$

(d) SST\&Precip LMO CFS

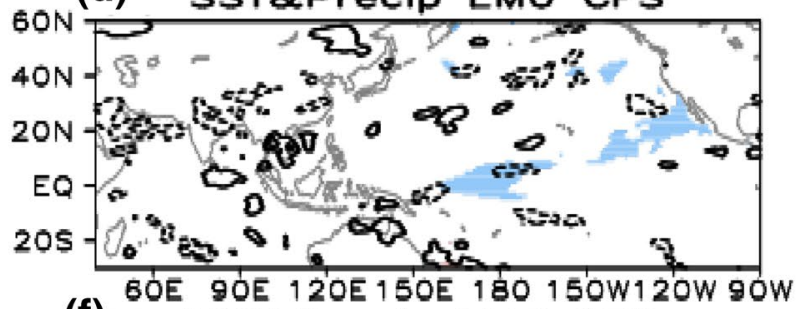

(f)

SST\&Precip LM3 CFS

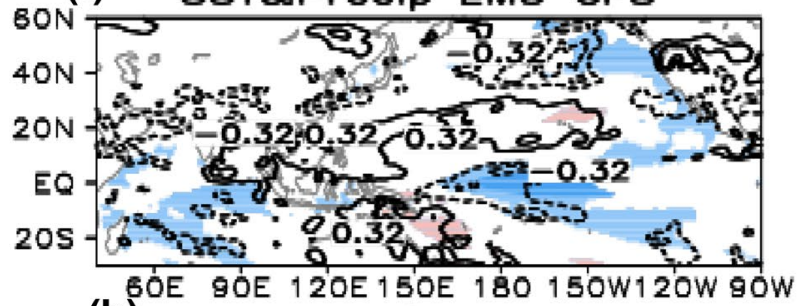

(h) SST\&Precip LM6 CFS

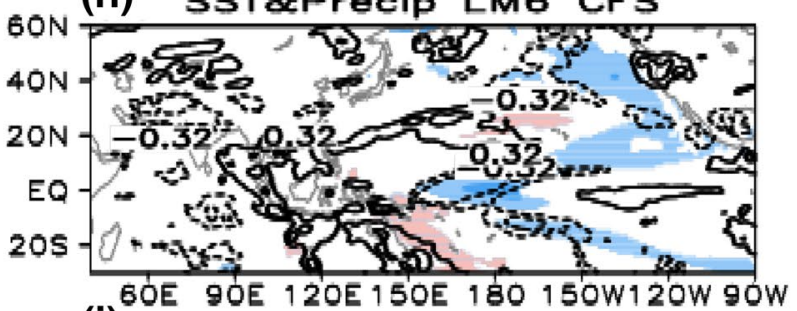

(j) SST\&Precip LMg CFS

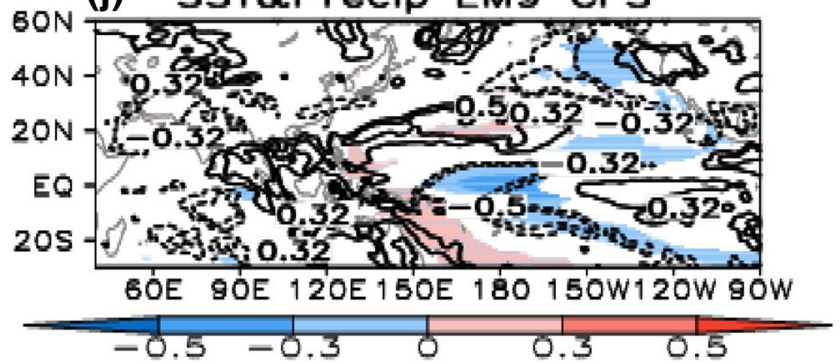

Fig. 8 Same as Fig. 6, but for the patterns of second MSN EOF PCs in March

phenomena of longer lead predictions outperforming shorter ones also occur in Asian monsoon predictions (e.g., Chattopadhyay et al. 2015; Saha et al. 2016). We speculate that, for those hindcasts initialized at times in the spring predictability barrier, the predictions may be more sensitive to the perturbations in the initial conditions and more vulnerable to the initial shock (Shukla et al. 2017).

The MSN EOF patterns in March (Fig. 7) are dominated by the easterly wind anomalies in the western Pacific. It is worth noticing that the westerly anomalies further to the east are also important features in the MSN EOF2s in earlier months from winter to spring, which have largely ended in March. Furthermore, the monthly evolution of the second predictable patterns within late winter and spring seasons is characterized by a southward shift of maximum westerly wind anomalies from the equator to the Southern Hemisphere, shown by the average between $160^{\circ} \mathrm{W}-140^{\circ} \mathrm{W}$ of the second MSN spatial pattern from November to next June (Fig. 9). This southward shift generally begins at November and ends in late winter or early spring (Fig. 9), generated 


\section{Southward Shift of Westerly Wind Anomalies}

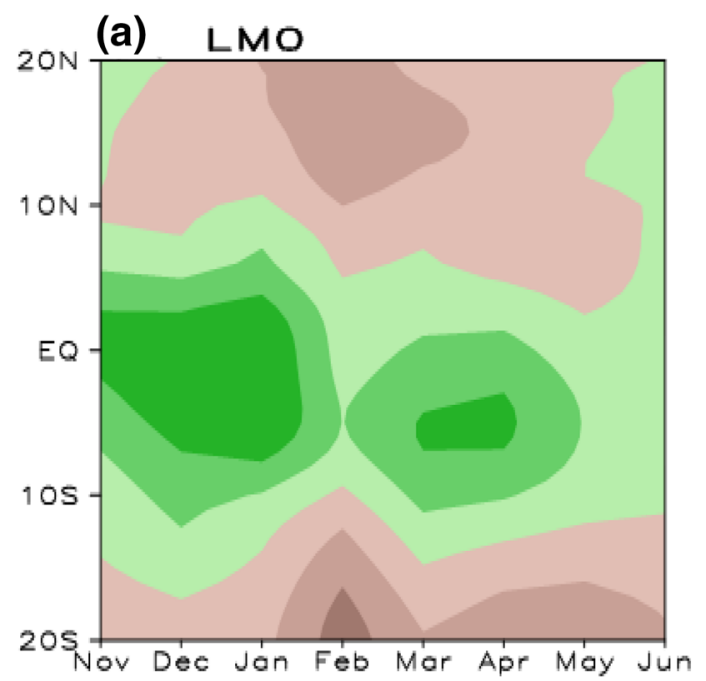

(b) LM3

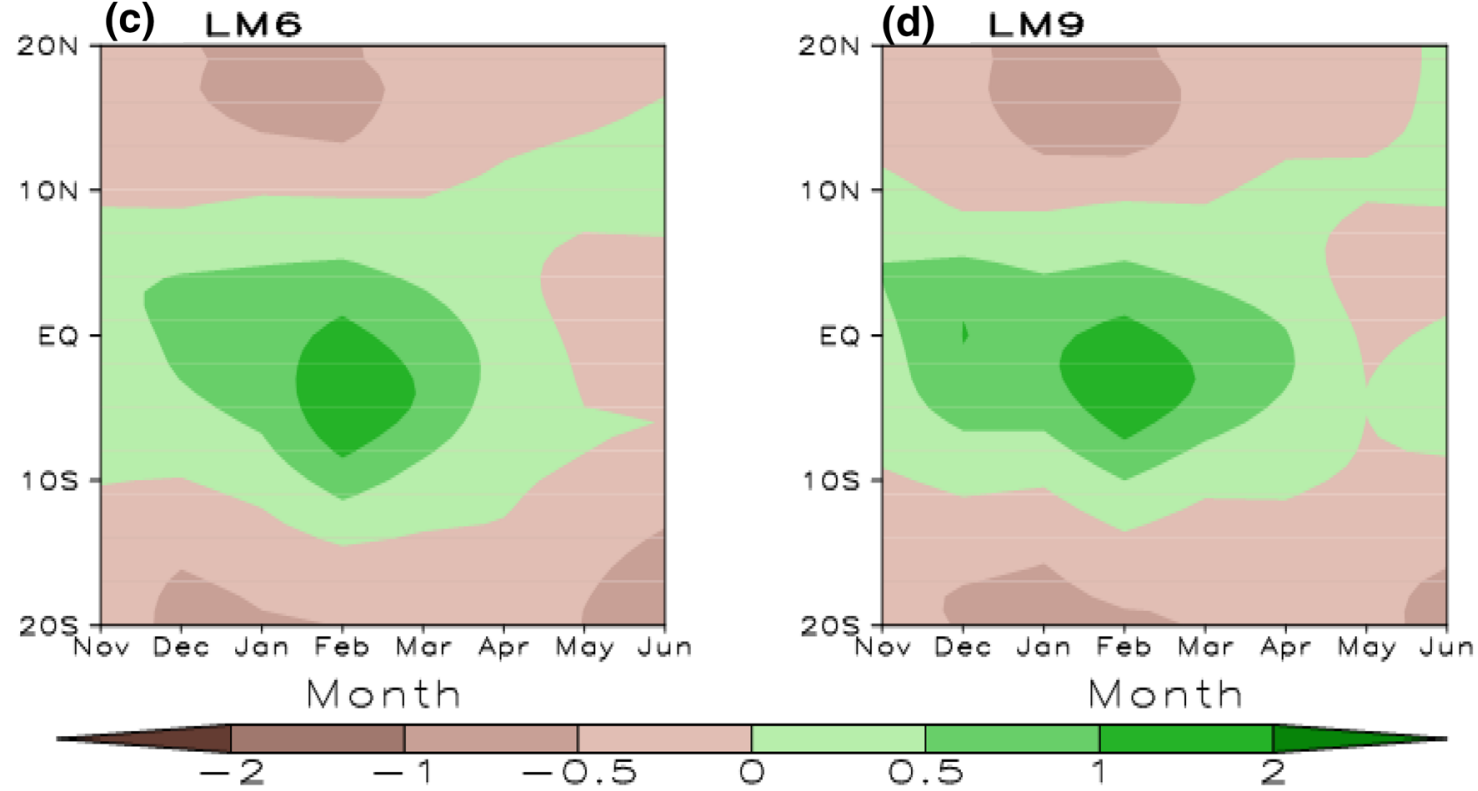

Fig. 9 Time-latitude (averaged between $160^{\circ} \mathrm{W}-140^{\circ} \mathrm{W}$ ) sections of the second MSN EOF modes in hindcast ensemble mean of a 0 -month lead, b 3-months lead, c 6-months lead, and d 9-months lead

by the C-mode, and may contribute to the phase transition processes of anomalous circulation over the WNP and of ENSO (McGregor et al. 2012; Stuecker et al. 2013, 2015), as we have discussed in the Introduction. The CFSv2 hindcast generally captures this southward shift up to LM9 (Fig. 9). In particular, the southward shift of westerly wind anomalies is accompanied by a slight southward shift of easterly wind anomalies over the western tropical Pacific, to a much less extent (Fig. 10), consistent with previous studies (Stuecker et al. 2013, 2015). Also, the major features of this southward shift of easterly wind anomalies are captured by the model up to LM9, but with smaller magnitudes in longer leads (Fig. 10). Similar features of those southward shifts can be seen from the second EOF modes in observation (resembling those in LM0 to a large extent) within late winter and spring seasons (figure not shown).

As a case study, anomalies of rainfall, SST, and $850-\mathrm{hPa}$ winds in November 1997 (left panels) and March 1998 (right panels) for observations and hindcast ensemble means of different leads are given in Fig. 11. In November 1997, strong anomalous westerly winds prevail over the equatorial Pacific (east of $170^{\circ} \mathrm{E}$ ) with positive SST and rainfall anomalies, and are accompanied by a weak anticyclonic circulation anomalies to its northwest with negative SST and rainfall anomalies (Fig. 11a). In the following months, the anomalous westerly winds as well as the anomalous easterly winds 

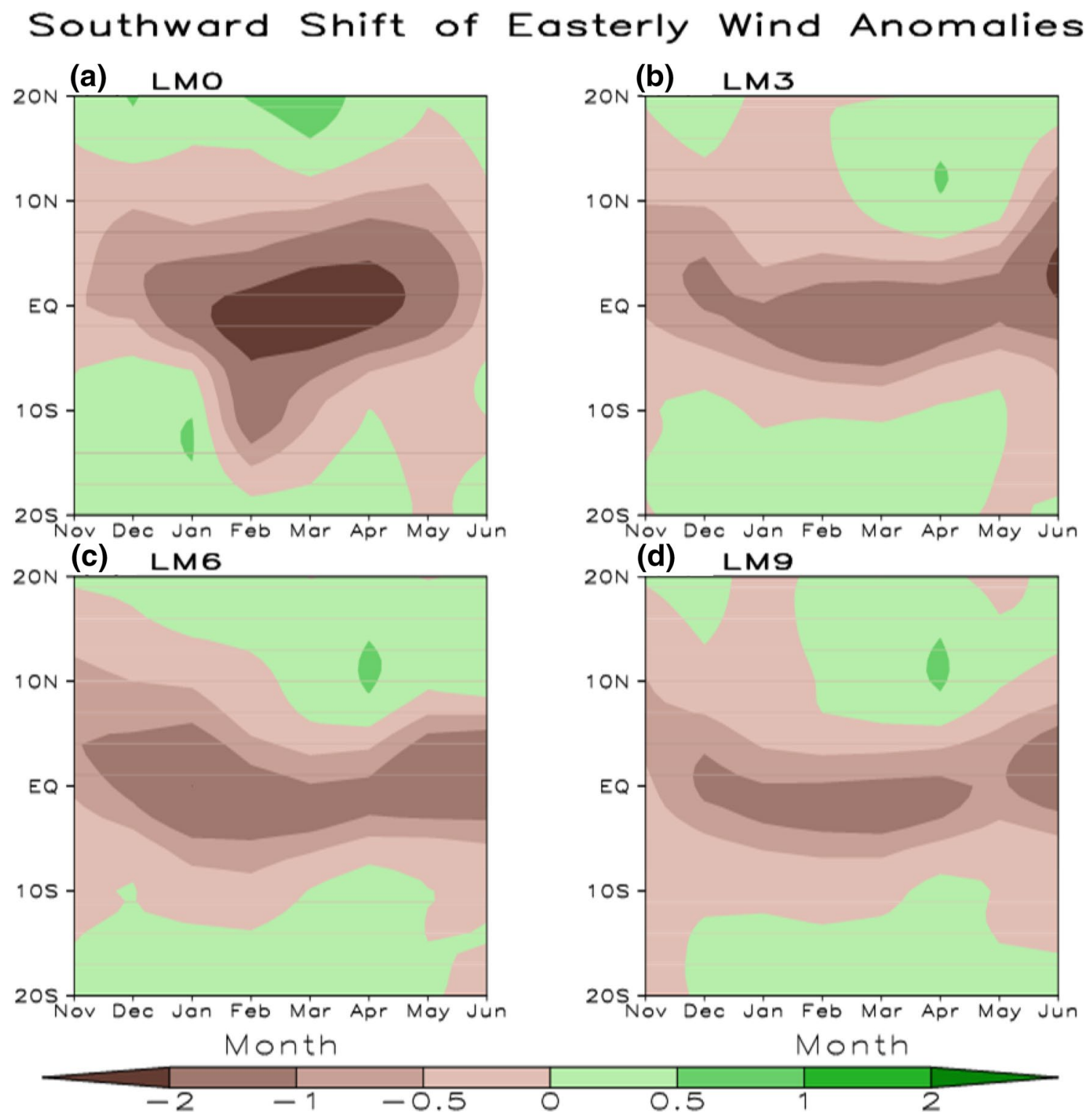

Fig. 10 Time-latitude (averaged between $130^{\circ} \mathrm{E}-170^{\circ} \mathrm{E}$ ) sections of the second MSN EOF modes in hindcast ensemble mean of a 0 -month lead, b 3-months lead, c 6-months lead, and d 9-months lead

over the western tropical Pacific, attributed to the anomalous WNP-AC, keep shifting southward until March in the following year (Fig. 11a, b). These characteristics are consistent with the features depicted above for the second most predictable patterns during winter and spring. Despite some discrepancies such as an overestimation of the anomalous easterly winds, the CFSv2 hindcast well captures the major features in short lead months (Fig. 11). However, large bias appears when lead time is longer than 4 months, especially for winter season months (Fig. 11g).

According to Fig. $4 \mathrm{~b}$, the second predictable patterns in longer leads (LM5-LM9) of summer months are also closely linked to the SST over the equatorial central Pacific. As an example, the second modes of 850-hPa zonal wind for LM6 and LM9 in July are shown in Fig. 12e-h. The percentages of variance of the ensemble mean explained by these MSN EOF2s in July are 23.4 and 23.1 for LM6 and LM9, respectively. The spatial patterns of MSN EOF2 in LM6 and LM9 are mainly characterized by opposite variations of anomalous zonal winds over the equatorial Pacific and the regions to its north and south, as well as over the equatorial IO (Fig.12e, g). The correlations and regression patterns for ensemble mean PC2s in longer leads show features of ENSO (Fig. 13e-h), and are generally well predicted by the CFSv2 hindcast except some overestimations (figures not shown). Although the MSN EOF1 shows a dip of skill at 


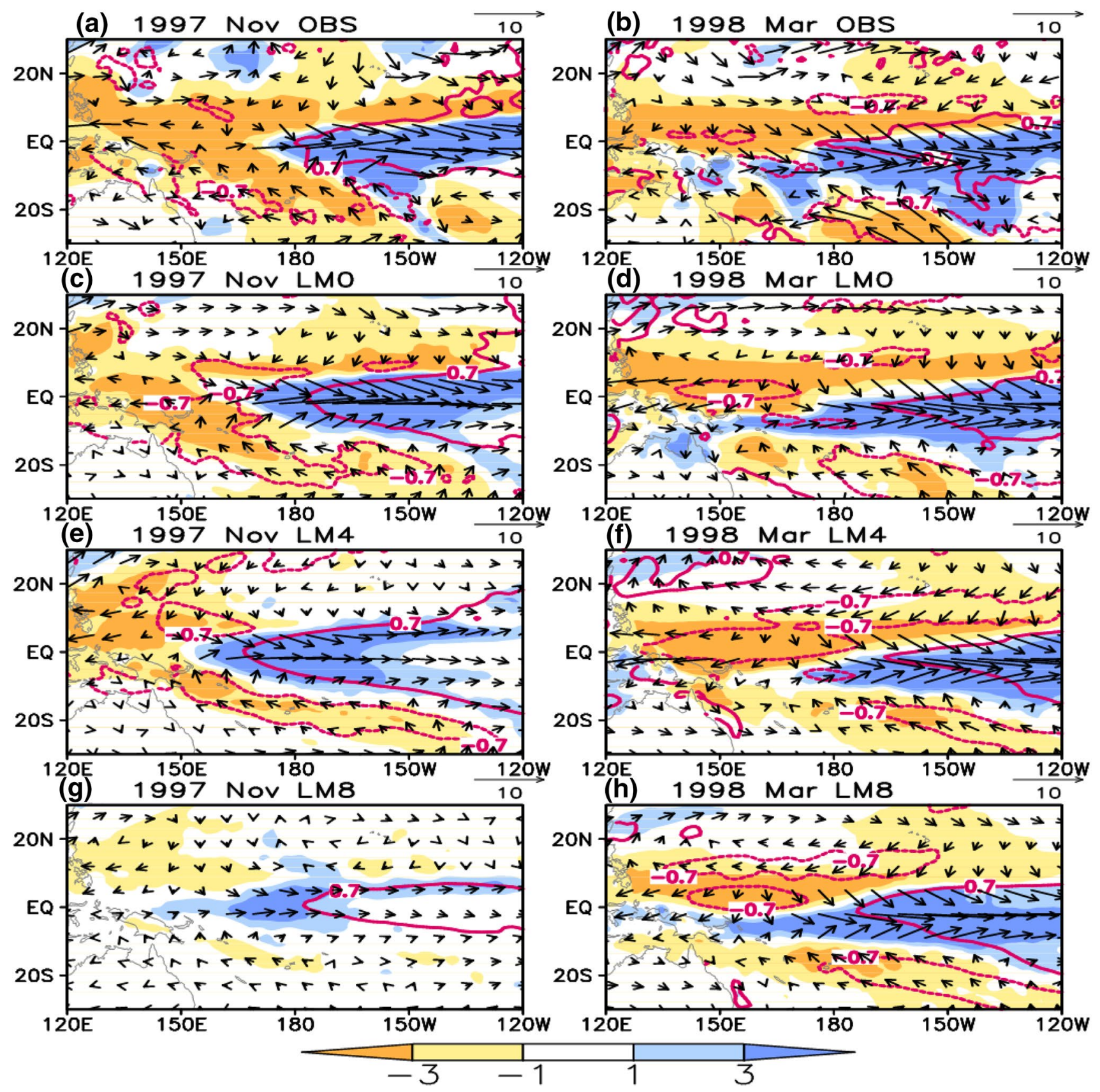

Fig. 11 Anomalies of rainfall (shading), SST (contours), and 850-hPa winds (vectors) in November 1997 (left panels) and March 1998 (right panels) for observations $(\mathbf{a}, \mathbf{b})$, hindcast ensemble mean of 0-month lead $(\mathbf{c}, \mathbf{d}), 4$-month lead $(\mathbf{e}, \mathbf{f})$, and 8-month lead $(\mathbf{g}, \mathbf{h})$

longer leads for summer months, the MSN EOF2 seems to pick it up (Figs. 3, 12e-h, 13e-h). This feature seems to suggest that the ENSO-related signals in summer are predictable on multi-seasonal leads.

\section{Predictable patterns within a season}

Predictable signals migrate seasonally from the central-toeastern equatorial Pacific (boreal winter and spring) to the
IO (fall), as shown by the second MSN EOF modes (Figs. 7, $12,14)$. The second most predictable patterns in short leads of summer months and fall months are mainly associated with WNP-AC and IOD, respectively (Fig. 4c, d).

\subsection{Predictable WNP monsoon patterns}

As an example, the second MSN EOF modes in different lead months for July are shown in Fig. 12. In short lead months (e.g., LM0 and LM3), the spatial patterns of MSN 


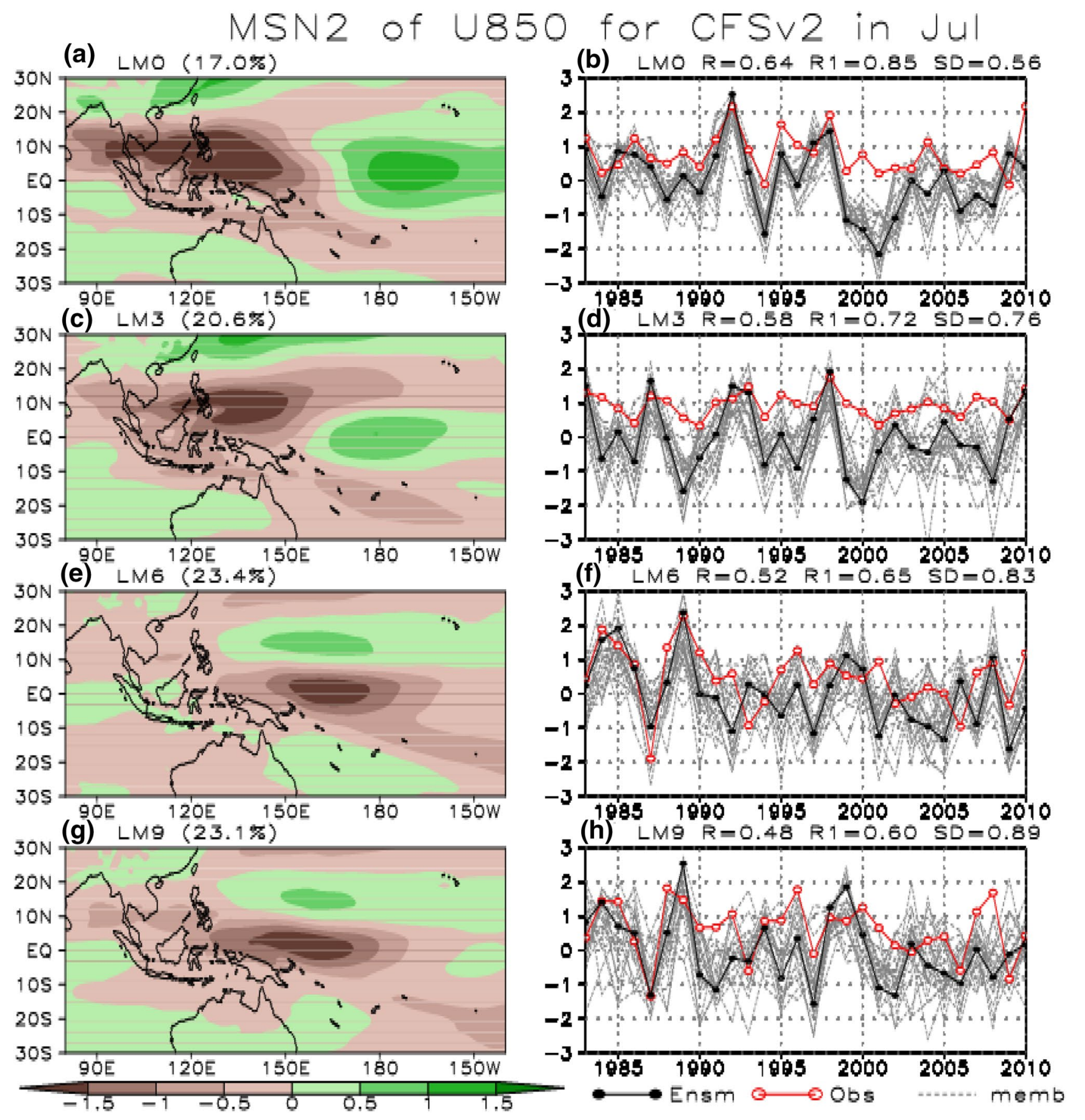

Fig. 12 Same as Fig. 5, but for the second MSN EOF modes in July

EOF2 are characterized by opposite variations of anomalous zonal winds around the Philippines and over the regions to its east, north, and south (Fig. 12a, c). This mode of MSN EOF in July related to the anomalous WNP-AC can be well predicted up to LM3, as shown by the significant correlations of the ensemble mean PCs with the projected PCs of observation and ensemble members within 3-months lead, in spite of an overestimation of the magnitude for time series (Figs. 3b, 12b, d).
In short lead months, the positive values of PC2s in July are mainly linked to positive SLP anomalies and an anomalous anticyclonic circulation over the WNP, warming (positive rainfall anomalies) in the central-eastern Pacific and the northern IO, and cooling (negative rainfall anomalies) in the northwest and southwest of the warming region (Fig. 13a-d). These characteristics match well with the features associated with the WNP monsoon (Wang et al. 1999; Wu and Wang 2000; Li and Wang 2005). 
(a) SLP\&UV85O LMO

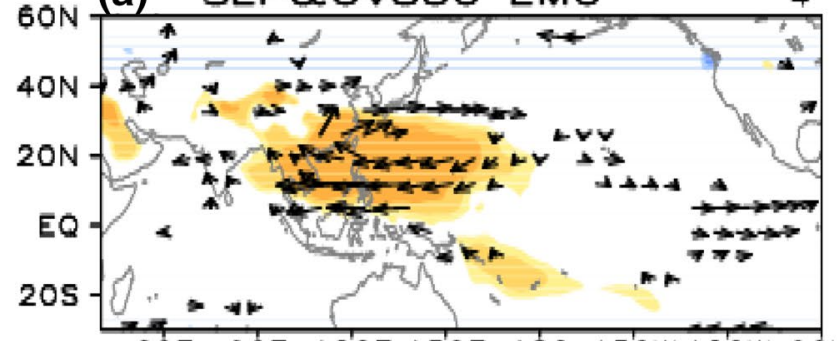

6OE SOE 12OE 15OE 180 15OW $120 \mathrm{~W}$ SOW

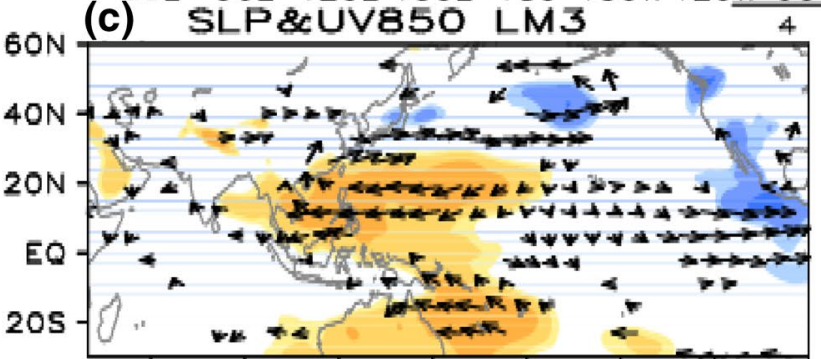

6OE 9OE $120 E 150 E 180150 W 120 W$ gOW

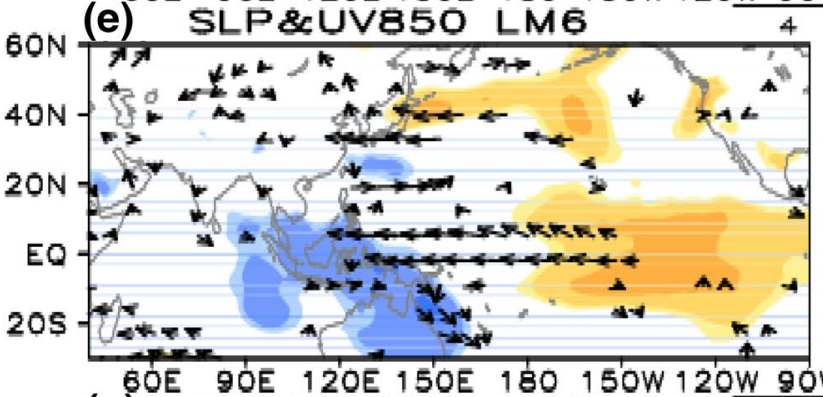

$60 E$ 9OE 120E 150E $180150 \mathrm{~W} 120 \mathrm{~W}$ 9OW

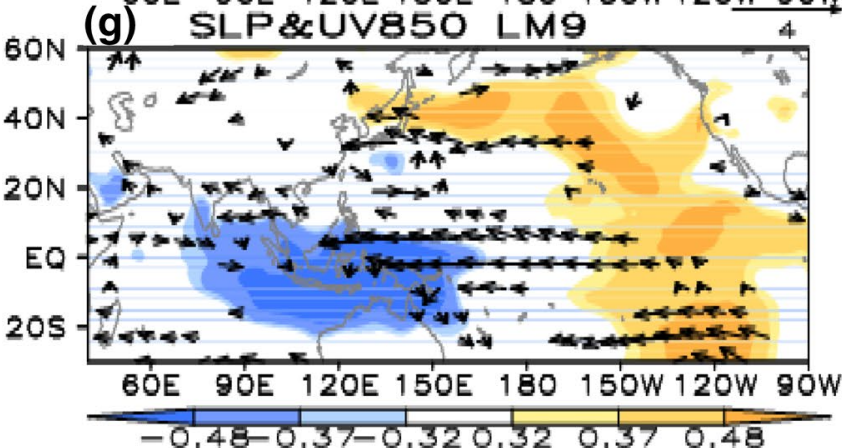

Fig. 13 Correlations of observed SLP/rainfall with ensemble mean PC2s and regressions of observed $850-\mathrm{hPa}$ winds/SST against ensemble mean P2s in different lead months for July. Left panels show the
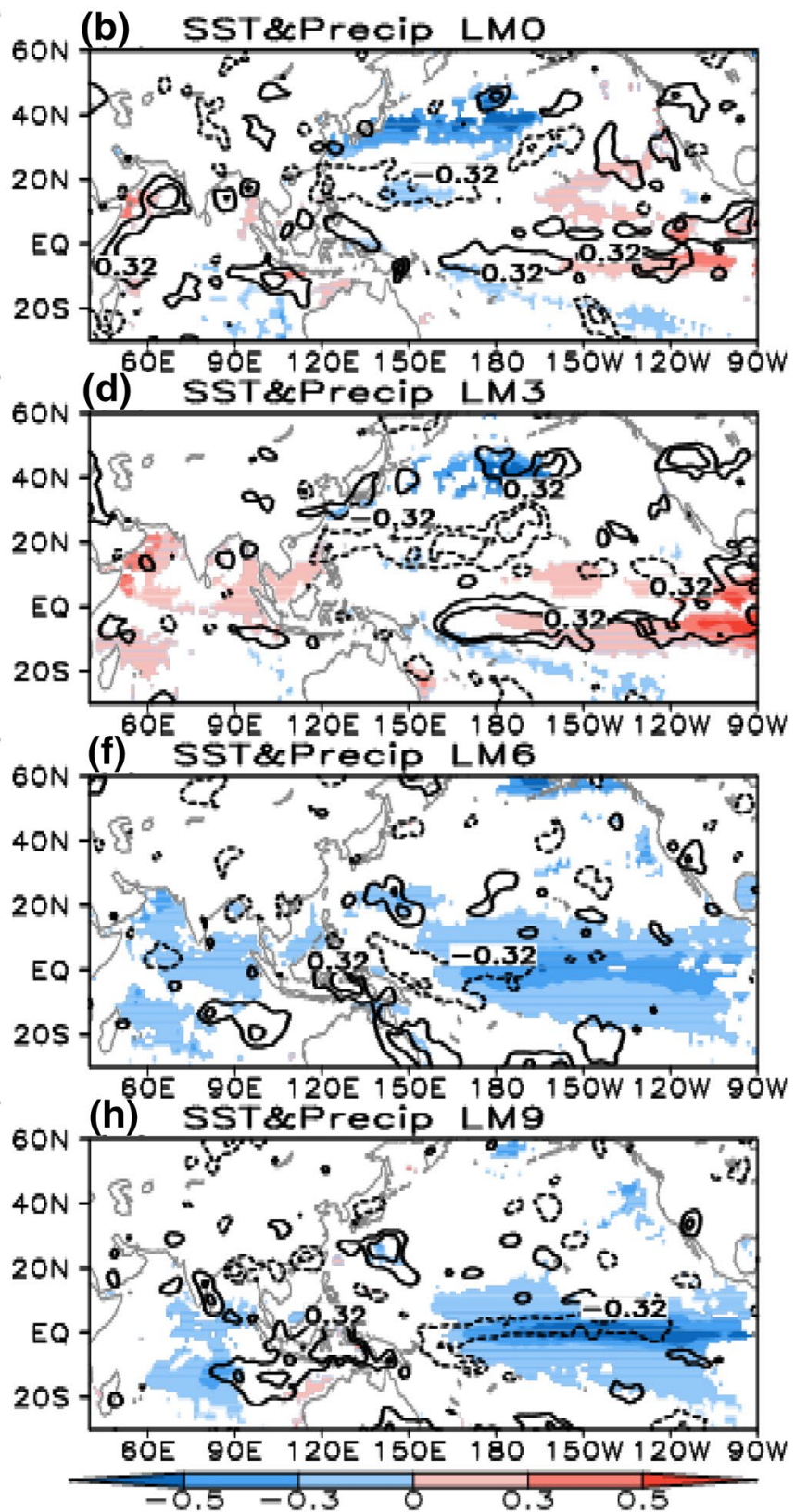

patterns for SLP (shading) and $850-\mathrm{hPa}$ winds (vectors) and right panels show the patterns for SST (shading) and rainfall (contours). Values exceeding the $90 \%$ confidence level are shown

LM6-LM9 in July (figures not shown), implying that the two may simply switch order from short to long leads. The most predictable patterns are associated with the WNP$\mathrm{AC}$ rather than ENSO at long leads (with initial months from late fall to early spring) may be due to the effect of "spring barrier" which limits the predictability of ENSO. The complicated relationships of the second most predictable patterns with ENSO, and with the WNP monsoon, may be due to the rapid transition of ENSO phase and the index exceeds the $95 \%$ confidence level of the $t$ test for 


\section{MSN2 of U850 for CFSV2 in Oct}

(a) LMO (9.8\%)
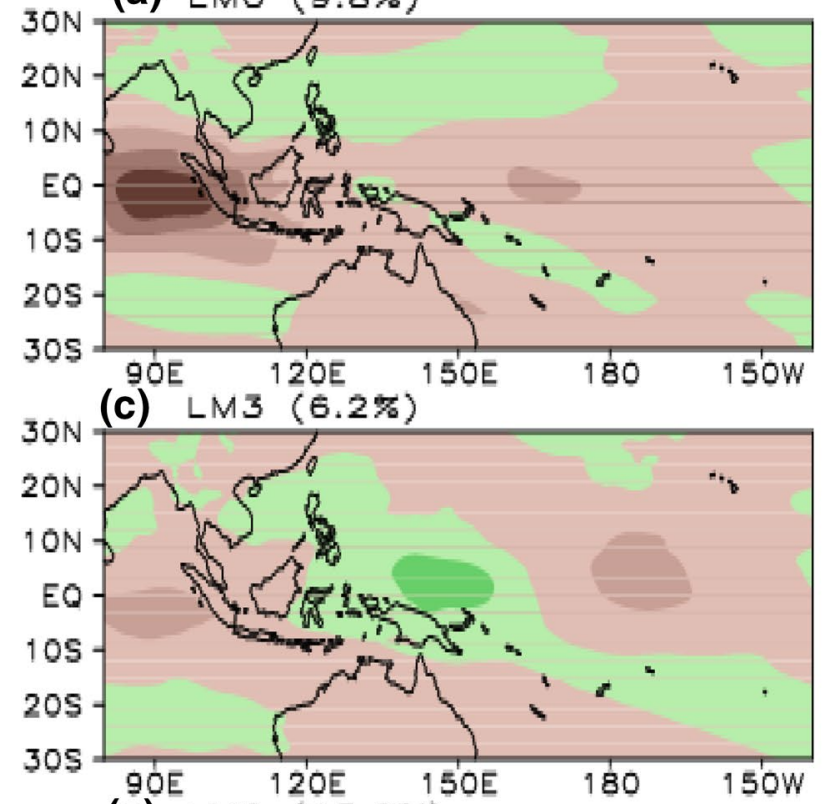

(e) LMG (13.0\%)

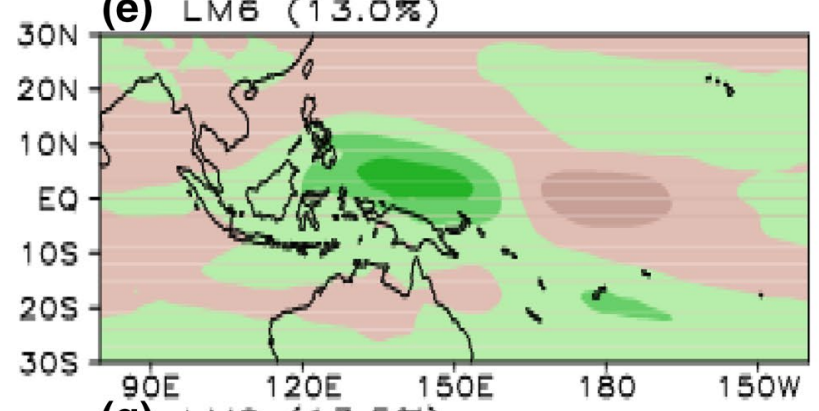

(g) LMG (13.5\%)

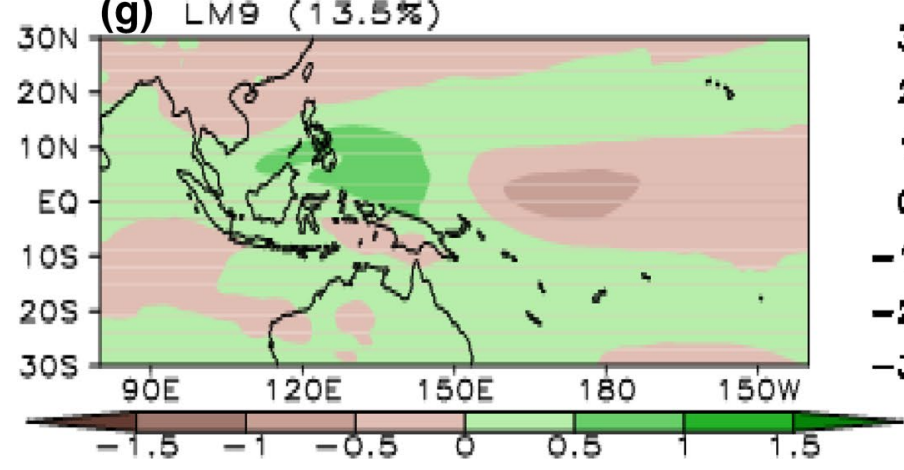

Fig. 14 Same as Fig. 5, but for the second MSN EOF modes in October

relationship between ENSO and the WNP monsoon during the summer season.

\subsection{Seasonal dependence of the IOD predictability}

In fall, the second MSN EOF modes are mainly associated with the IOD, as shown by the significant correlations between the ensemble mean PC2s and the IOD indices (b) LMO $\mathrm{R}=0.70 \mathrm{R} 1=0.79 \mathrm{SD}=0.64$
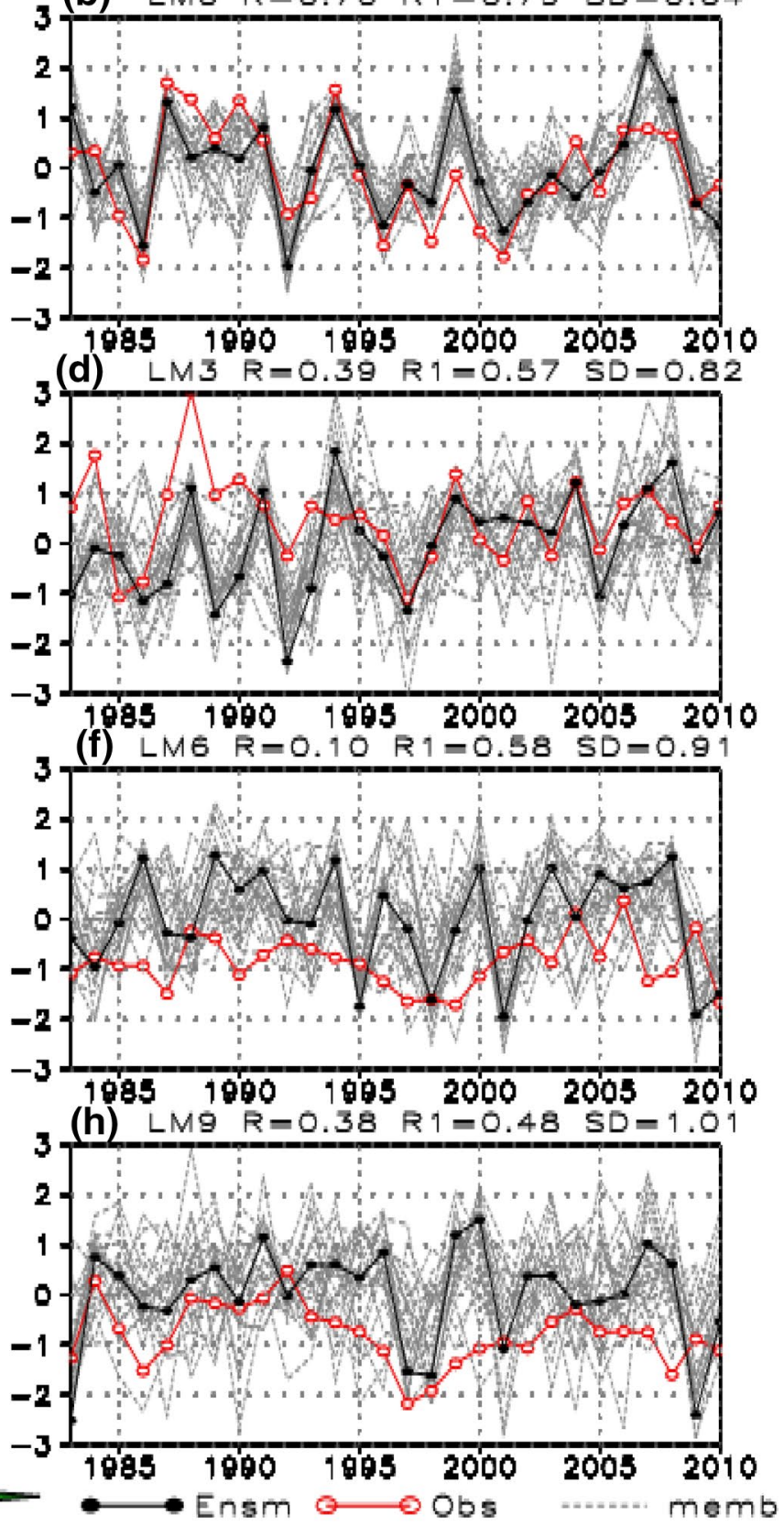

(Fig. 4d). Figure 14a indicates that the second MSN EOF mode of LM0 in October is mainly characterized by signals over the tropical IO. The percentages of variance of the ensemble mean explained by these MSN EOF2s in October are 9.8, 6.2, 13.0, and 13.5 for LM0, LM3, LM6, and LM9, respectively, generally smaller than those in other season months. For the time series of LM0, some of the peaks and valleys correspond to the IOD events (e.g., 1984, 1987, 
1992, and 1994), but some are not (e.g., 1999 and 2007) (Fig. 14b). Spreads among the individual members and the discrepancies between observations and CFSv2 ensemble means become larger with the increase in lead time, and the correlations between MSN PC2s and projected PC2s (of observation and individual members) are insignificant after LM3 (see right panels of Fig. 14).

The second mode of MSN EOF in October is linked to negative SLP anomalies accompanied by an anomalous cyclonic circulation over the western tropical IO, positive SLP anomalies over the Pacific, and anomalous easterlies near the equatorial IO which bridges the western pole (accompanied by increased rainfall and SST) and the eastern pole (accompanied by decreased rainfall and SST) of IOD. Signals are weaker for the MSN EOF2 modes of different lead months in October and there is little signal when lead time is longer than 3 months (Figs. 14, 15), suggesting lower predictability of this mode compared to the second most predictable modes in other seasons.

In September, the second MSN EOF mode can only be well predicted by the CFSv2 hindcast about one season ahead and is associated with IOD only in LM0 (Figs. 3b, 4d). Signals are also weaker for the second MSN EOF mode in September (figure not shown). On the other hand, the second MSN EOF mode in November shows complicated relationships with the anomalous WNP anticyclone/cyclone circulation and IOD (Fig. 4c, d). This mode in November can be skillfully predicted by the CFSv2 two seasons in advance (Fig. 3b). The better prediction skill for the second MSN EOF mode in November compared to that for September and October may be attributed to longer persistence of the anomalous WNP anticyclone/cyclone circulation.

\section{Discussion and conclusions}

In this work, we have investigated the seasonality of the predictable patterns of 850 -hPa zonal wind over the tropical Indo-Pacific domain, using the NCEP CFSv2 monthly hindcasts. Motivated by the apparent seasonality of correlation skills in different areas, the most predictable patterns are further identified using the MSN EOF method for each of the target months. Furthermore, the prediction skills of these predictable patterns and their associated climate variations are investigated to understand the sources of the predictability.

For the first MSN EOF modes, the MSN PC1s are significantly correlated with the Niño-3.4 SST indices, as well as the Niño-3 and Niño-4 SST indices, and the characteristics of correlation and regression patterns for ensemble mean PC1s are similar to the features of the developing and maturing phases of ENSO for all the months from late summer to winter and spring. This feature suggests that ENSO is the dominant factor of the most predictable patterns of $850-\mathrm{hPa}$ zonal wind over the Indo-Pacific region. These modes are generally well captured by the CFSv2 hindcast 9 months in advance, except for May-June when the effect of the spring predictability barrier is strong. Therefore, ENSO is the major source of predictability of low-level atmospheric circulation variations over the tropical Indo-Pacific region.

Compared to the most predictable patterns (i.e., ENSO signals), the influences of other climate processes on the predictability of low-level atmospheric circulation are more seasonally dependent. For winter and spring, the second most predictable patterns are associated with the decaying phase of ENSO. Significantly (insignificantly) correlations between the PC2s of ensemble mean and the Niño-4 (Niño3.4 or Niño-3) SST indices in winter and spring months suggest that the second most predictable patterns are closely linked to the SST over the equatorial central Pacific rather than that over the equatorial eastern Pacific during the two seasons. The CFSv2 hindcast well predicts the second predictable patterns at least 5-months in advance for spring months, while shows much lower skills for winter months. Besides spring and winter, the second predictable patterns in longer leads (LM5-LM9) of summer months are also closely linked to the SST anomalies over the equatorial central Pacific and are generally well predicted by the CFSv2 hindcast.

It should be noted that within the winter and spring seasons, the monthly evolution of the second predictable patterns is characterized by a southward shift of westerly wind anomalies from the equator to the Southern Hemisphere, which is generated by the interaction between the warm pool annual cycle and ENSO signals (i.e., the combination-mode) and plays an important role in the termination of strong El Niño events (Stuecker et al. 2013, 2015). This southward shift of westerly wind anomalies is accompanied by a southward shift of easterly wind anomalies over the tropical western Pacific, and both shifts are captured by the CFSv2 hindcast up to LM9, although with smaller magnitudes in longer leads.

In addition to the ENSO-related patterns that are predictable at multi-season leads, some phenomena are also predictable at seasonal lead. In the summer months, the second most predictable patterns at short leads are mainly associated with the WNP monsoon. These patterns are related to the WNP summer monsoon and can be well predicted by the CFSv2 hindcast about 3 months in advance. In the fall season, the second most predictable pattern picks up the zonal wind anomalies in the eastern equatorial IO that are associated with the IOD for September and October, and associated with the IOD and the WNP anticyclonic/cyclonic circulation for November. The CFSv2 can only well predicts the second most predictable patterns about one season ahead for September and October, while 


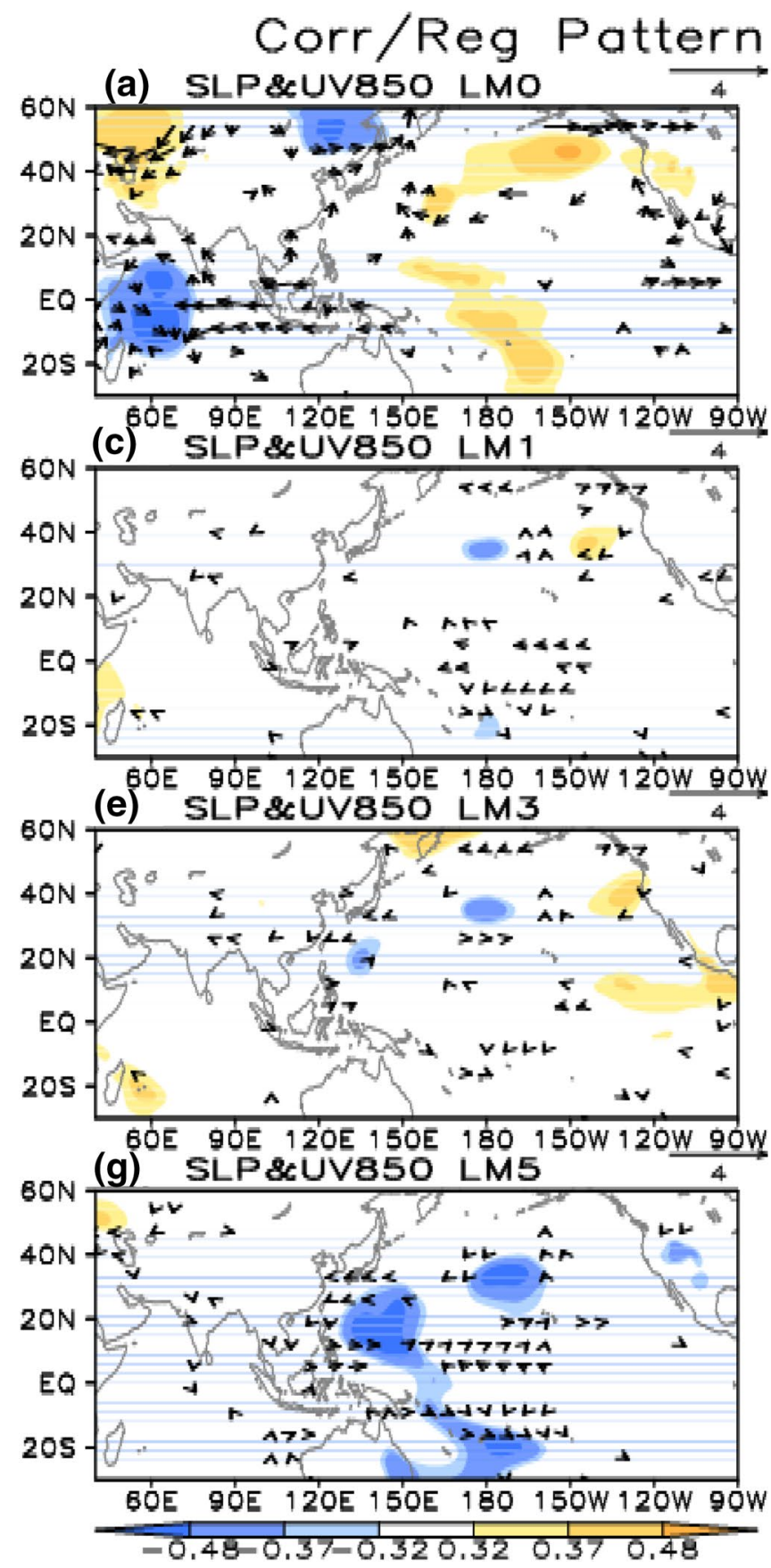

Fig. 15 Correlations of observed (a, b) and predicted (c-h) SLP/ rainfall with ensemble mean PC2s and regressions of $850-\mathrm{hPa}$ winds/ SST against ensemble mean PC2s in different leads for October. Left

about two seasons ahead for November. The better prediction skill for November may be attributed to the longer persistence of the anomalous WNP anticyclone/cyclone circulation. Furthermore, the relatively lower prediction skills of the IOD related and the WNP monsoon related patterns compared to those ENSO related patterns are partly due to the seasonal nature (i.e., large seasonality) of the IOD and the WNP monsoon.

\section{for $\mathrm{PC} 2$ in Oct}

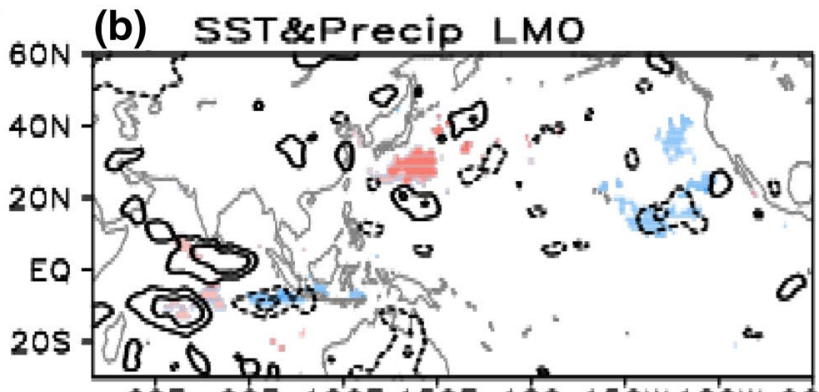

GÓ
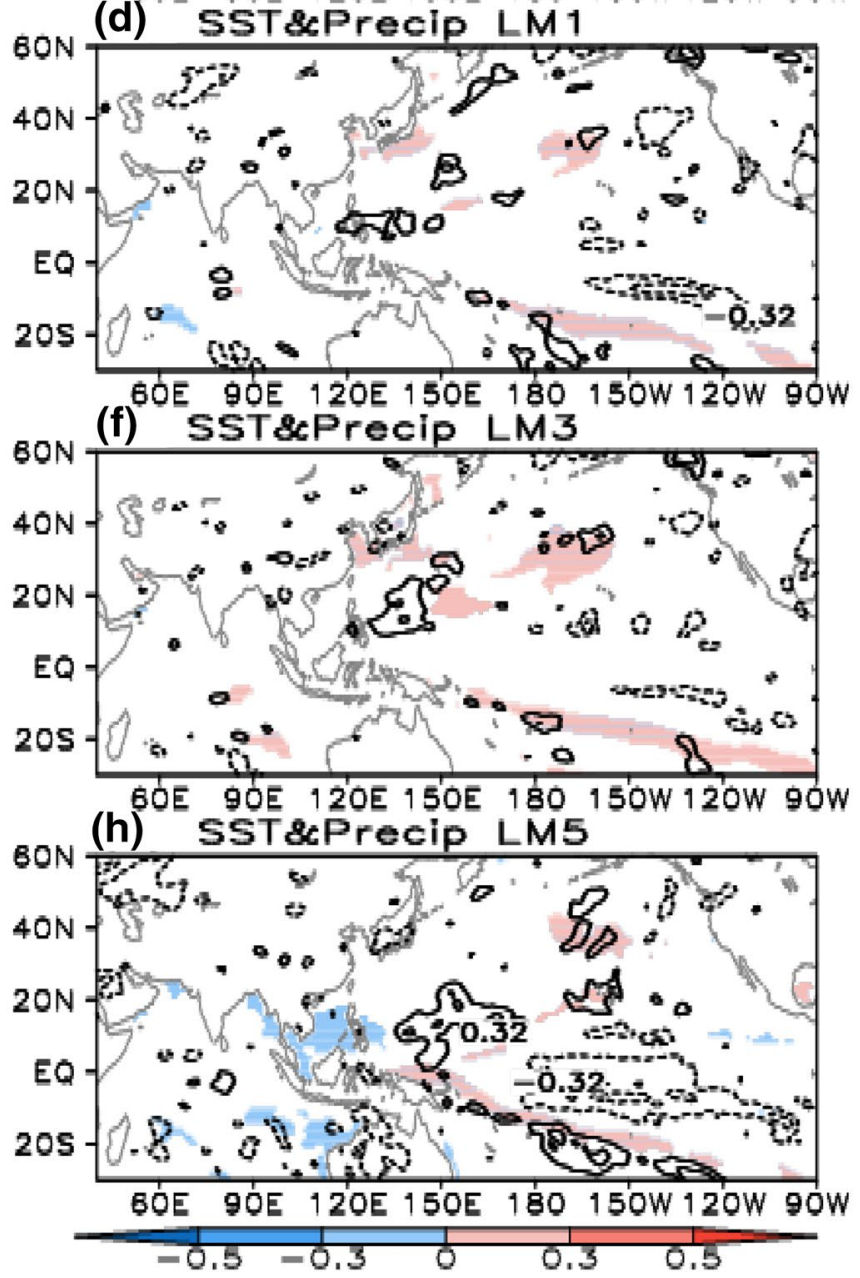

panels show the patterns for SLP (shading) and $850-\mathrm{hPa}$ (vectors) winds and right panels show the patterns for SST (shading) and rainfall (contours). Values exceeding the $90 \%$ confidence level are shown

Acknowledgements The authors thank the two anomalous reviewers for their constructive comments on an earlier version of the manuscript. This study was jointly supported by the National Key Scientific Research Plan of China (Grant 2014CB953904), the National Key Research and Development Program of China (2016YFA0602703), the Natural Science Foundation of China (Grants 41661144019, 41690123, 41690120, 41375081), the LASW State Key Laboratory Special Fund (2016LASW-B01), the CMA Guangzhou Joint Research Center for Atmospheric Sciences, the Jiangsu Collaborative Innovation Center for Climate Change, and the CMA Guangzhou Institute 
of Tropical and Marine Meteorology/Guangdong Provincial Key Laboratory of Regional Numerical Weather Prediction. B. Huang is supported by grants from the National Science Foundation (AGS1338427), the National Oceanic and Atmospheric Administration (NA14OAR4310160), and the National Aeronautics and Space Administration (NNX-14AM19G).

Open Access This article is distributed under the terms of the Creative Commons Attribution 4.0 International License (http://creativecommons.org/licenses/by/4.0/), which permits unrestricted use, distribution, and reproduction in any medium, provided you give appropriate credit to the original author(s) and the source, provide a link to the Creative Commons license, and indicate if changes were made.

\section{References}

Allen MR, Smith LA (1997) Optimal filtering in singular spectrum analysis. Phys Lett 234:419-428

Barnston AG, Tippett MK, L'Heureux ML, Li S, DeWitt DG (2012) Skill of real-time seasonal ENSO model predictions during 2002-2011-Is our capability increasing? Bull Amer Meteor Soc 93:631-651

Bjerknes J (1969) Atmospheric teleconnections from the equatorial Pacific. Mon Weather Rev 97:163-172

Cai W, Rensch PV, Cowan T, Hendon HH (2011) Teleconnection pathways of ENSO and the IOD and the mechanisms for impacts on Australian rainfall. J Clim 24:3910-3923. doi:10.1175/2011J CLI4129.1

Chang P, Saravanan R, Ji L, Hegerl GC (2000) The effect of local sea surface temperatures on atmospheric circulation over the tropical Atlantic sector. J Clim 13:2195-2216

Chattopadhyay R, Rao SA, Sabeerali CT, George G, Rao DN, Dhakate A, Salunke K (2015) Large-scale teleconnection patterns of Indian summer monsoon as revealed by CFSv2 retrospective seasonal forecast runs. Int J Climatol. doi:10.1002/joc.4556

Gill A (1980) Some simple solutions for heat-induced tropical circulation. Quart J Roy Meteor Soc 106:447-462

Harrison DE (1987) Monthly mean island surface winds in the central tropical Pacific and El Niño events. Mon Weather Rev 115:3133-3145

Harrison DE, Vecchi GA (1999) On the termination of El Niño. Geophys Res Lett 26:1593-1596

Haylock M, McBride J (2001) Spatial coherence and predictability of Indonesian wet season rainfall. J Clim 14:3882-3887

Hendon HH (2003) Indonesian rainfall variability: impacts of ENSO and local air-sea interaction. J Clim 16:1775-1790

Huang B (2004) Remotely forced variability in the tropical Atlantic Ocean. Clim Dyn 23:133-152

Huang B, Kinter III JL (2002) Interannual variability in the tropical Indian Ocean. J Geophys Res 107(C11):3199

Hu Z-Z, Huang B (2007) The predictive skill and the most predictable pattern in the tropical Atlantic: the effect of ENSO. Mon Weather Rev 135:1786-1806

Jia X, Lin H (2013) The possible reasons for the misrepresented long-term climate trends in the seasonal forecasts of HFP2. Mon Weather Rev 141:3154-3169

Jiang X, Yang S, Li J, Li Y, Hu H, Lian Y (2013a) Variability of the Indian Ocean SST and its possible impact on summer western North Pacific anticyclone in the NCEP climate forecast system. Clim Dyn 41:2199-2212

Jiang X, Yang S, Li Y, Kumar A, Wang W, Gao Z (2013b) Dynamical prediction of the East Asian winter monsoon by the NCEP climate forecast system. J Geophys Res 118:1312-1328
Kao H-Y, Yu J-Y (2009) Contrasting Eastern-Pacific and CentralPacific types of ENSO. J Clim 22:615-632

Kosaka Y, Xie S-P (2013) Recent global-warming hiatus tied to equatorial Pacific surface cooling. Nature 501:403-407

Lau K-M, Yang S (1996) The Asian monsoon and predictability of the tropical ocean-atmosphere system. Quart J Roy Meteor Soc 122:945-957

Lau K-M, Kim K-M, Yang S (2000) Dynamical and boundary forcing characteristics of regional components of the Asian summer monsoon. J Clim 13:2461-2482

Lau K-M, Li X, Wu HT (2002) Evolution of the large scale circulation, cloud structure and regional water cycle associated with the South China Sea monsoon during May-June, 1998. J Meteor Soc Jpn 80:1129-1147

Li T, Wang B (2005) A review on the western North Pacific monsoon: synoptic-to-interannual variabilities. Terr Atmos Ocean Sci 16:285-314

Li T, Wang B, Wang L (2016) Comments on "combination mode dynamics of the anomalous Northwest Pacific anticyclone. J Clim 29:4685-4693

Liang JY, Yang S, Hu ZZ, Huang B, Kumar A, Zhang Z (2009) Predictable patterns of the Asian and Indo-Pacific summer precipitation in the NCEP CFS. Clim Dyn 32:989-1001

Lindzen RS, Nigam S (1987) On the role of sea surface temperature gradients in forcing low-level winds and convergence in the tropics. J Atmos Sci 44:2418-2436

LinHo LH, Huang X, Lau N-C (2008) Winter-to-spring transition in East Asia: a planetary-scale perspective of the South China spring rain onset. J Clim 21:3081-3096

McGregor S, Timmermann A, Schneider N, Stuecker MF, England MH (2012) The effect of the South Pacific convergence zone on the termination of El Niño events and the meridional asymmetry of ENSO. J Clim 25:5566-5586

Murakami T, Matsumoto J (1994) Summer monsoon over the Asian continent and western North Pacific. J Meteor Soc Jpn 72:719-745

Neelin JD, Battisti DS, Hirst AC, Jin F-F, Wakata Y, Yamagata T, Zebiak SE (1998) ENSO theory. J Geophys Res 103:14261-14290

Ramage CS (1968) Role of a tropical "maritime continent" in the atmospheric circulation. Mon Weather Rev 96:365-369

Rasmuson EM, Carpenter T (1982) Variations in tropical sea surface temperature and surface winds associated with the Southern Oscillation/El Niño. Mon Weather Rev 110:354-384

Reynolds RW, Smith TM, Liu C, Chelton DB, Casey KS, Schlax MG (2007) Daily high-resolution blended analyses for sea surface temperature. J Clim 20:5473-5496

Saha S, Nadiga S, Thiaw C et al (2006) The NCEP climate forecast system. J Clim 19:3483-3517

Saha S, Moorthi S, Pan H-L et al (2010) The NCEP climate forecast system reanalysis. Bull Am Meteorol Soc 91:1015-1057

Saha S, Moorthi S, Wu X et al (2014) The NCEP climate forecast system version 2. J Clim 27:2185-2208

Saha SK, Pokhrel S, Salunke K, Dhakate A, Chaudhari HS, Rahaman H, Sujith K, Hazra A, Sikka DR (2016) Potential predictability of Indian summer monsoon rainfall in NCEP CFSv2. J Adv Model Earth Syst 8:96-120. doi:10.1002/2015MS000542

Saji NH, Goswami BN, Vinayachandran PN, Yamagata T (1999) A dipole mode in the tropical Indian Ocean. Nature 401:360-363

Shukla RP, Huang B, Marx L, Kinter JL, Shin C-S (2017) Predictability and prediction of Indian summer monsoon by CFSv2: implication of the initial shock effect. Clim Dyn. doi 10.1007/ s00382-017-3594-0

Stuecker MF, Timmermann A, Jin F-F, McGregor S, Ren H-L (2013) A combination mode of the annual cycle and the El Niño/Southern Oscillation. Nat Geosci 6:540-544 
Stuecker MF, Jin F-F, Timmermann A, McGregor S (2015) Combination mode dynamics of the anomalous Northwest Pacific anticyclone. J Clim 28:1093-1111

Sun Y, Zhou T (2013) How does El Niño affect the interannual variability of the boreal summer Hadley circulation? J Clim 27:2622-2642

Sutton RT, Jewson SP, Rowell DP (2000) The elements of climate variability in the tropical Atlantic region. J Clim 13:3261-3284

Torrence C, Webster PJ (1998) The annual cycle of persistence in the El Niño-Southern Oscillation. Q J R Meteorol Soc 124:1985-2004

Venzke S, Allen MR, Sutton RT, Rowell DP (1999) The atmospheric response over the North Atlantic to decadal changes in sea surface temperature. J Clim 12:2562-2584

Wang B, Zhang Q (2002) Pacific-East Asian teleconnection. Part II: How the Philippine Sea anomalous anticyclone is established during El Niño development. J Clim 15:3252-3265

Wang B, Wu R, Lukas R (1999) Role of the western North Pacific wind variation in thermocline adjustment and ENSO phase transition. $\mathrm{J}$ Meteorol Soc Jpn 77:1-16

Wang B, Wu R, Fu X (2000) Pacific-East Asian teleconnection: how does ENSO affect East Asian climate? J Clim 13:1517-1536

Wang B, Ding Q, Fu X, Kang I-S, Jin K, Shukla J, Doblas-Reyes F (2005) Fundamental challenges in simulation and prediction of summer monsoon rainfall. Geophys Res Lett 32:L15711. doi:10 $.1029 / 2005$ GL022734

Wang W, Chen M, Kumar A (2011) An assessment of the CFS real time seasonal forecasts. Weather Forecast 25:950-969

Weaver SJ, Wang W, Chen M, Kumar A (2011) Representation of MJO variability in the NCEP climate forecast system. J Clim 24:4676-4694

Webster PJ, Yang S (1992) Monsoon and ENSO: selectively interactive systems. Q J R Meteorol Soc 118:877-926

Wu R, Wang B (2000) Interannual variability of summer monsoon onset over the western North Pacific and the underlying processes. J Clim 13:2483-2501

Xie P, Arkin PA (1997) Global rainfall: a 17-year monthly analysis based on gauge observations, satellite estimates, and numerical model outputs. Bull Am Meteorol Soc 78:2539-2558

Xie S-P, Philander SGH (1994) A coupled ocean-atmosphere model of relevance to the ITCZ in the eastern Pacific. Tellus 46A:340-350
Xie S-P, Hu K, Hafner J, Tokinaga H, Du Y, Huang G, Sampe T (2009) Indian Ocean capacitor effect on Indo-western pacific climate during the summer following El Niño. J Clim 22:730-747

Xue Y, Chen M, Kumar A, Hu Z-Z, Wang W (2013) Prediction skill and bias of tropical Pacific sea surface temperatures in the NCEP climate forecast system version 2. J Clim 26:5358-5377

Yamagata T, Behera SK, Rao SA, Guan Z, Ashok K, Saji HN (2003) Comments on "dipoles, temperature gradient, and tropical climate anomalies." Bull Am Meteorol Soc 84:1418-1422

Yang S, Jiang X (2014) Prediction of eastern and central Pacific ENSO events and their impacts on East Asian climate by the NCEP climate forecast system. J Climate 27:4451-4472

Yu J-Y, Kao H-Y (2007) Decadal changes of ENSO persistence barrier in SST and ocean heat content indices: 1958-2001. J Geophys Res 112:D13106. doi:10.1029/2006JD007654

Yuan X, Wood EF, Luo L, Pan M (2011) A first look at climate forecast system version 2 (CFSv2) for hydrological seasonal prediction. Geophys Res Lett 38:L13402. doi:10.1029/2011GL047792

Zhang T, Yang S, Jiang X, Zhao P (2016a) Seasonal-interannual variation and prediction of wet and dry season rainfall over the maritime continent: roles of ENSO and monsoon circulation. J Clim 29:3675-3695

Zhang T, Yang S, Jiang X, Huang B (2016b) Roles of remote and local forcings in the variation and prediction of regional maritime continent rainfall in wet and dry seasons. J Clim 29:8871-8879

Zhang W, Jin F-F, Stuecker MF, Wittenberg AT, Timmermann A, Ren H-L, Kug J-S, Cai W, Cane M (2016c) Unraveling El Niño's impact on the East Asian monsoon and Yangtze river summer flooding. Geophys Res Lett 43:11,375-11,382. doi:10.1002/20 16GL071190

Zhu J, Huang B, Kumar A, Kinter III JL (2015) Seasonality in prediction skill and predictable pattern of tropical Indian Ocean SST. J Clim 28:7962-7984

Zuo Z, Yang S, Hu ZZ, Zhang R, Wang W, Huang B, Wang F (2013) Predictable patterns and predictive skills of monsoon rainfall in northern hemisphere summer in NCEP CFSv2 reforecasts. Clim Dyn 40:3071-3088 